\title{
Dynamic vs. Static Wholesale Pricing Strategies in a Dual-Channel Green Supply Chain
}

\author{
Yongzhao Wang $\mathbb{D}^{1}$ and Xiaojie Sun $\mathbb{D}^{2}$ \\ ${ }^{1}$ School of Mathematics and Statistics, Anyang Normal University, Anyang 455000, China \\ ${ }^{2}$ College of Management and Economics, Tianjin University, Tianjin 300072, China
}

Correspondence should be addressed to Xiaojie Sun; xjsun@tju.edu.cn

Received 13 May 2019; Accepted 3 September 2019; Published 11 November 2019

Academic Editor: José Manuel Galán

Copyright $\odot 2019$ Yongzhao Wang and Xiaojie Sun. This is an open access article distributed under the Creative Commons Attribution License, which permits unrestricted use, distribution, and reproduction in any medium, provided the original work is properly cited.

With the improvement of social environmental awareness, the dual-channel green product sales mode has been widely used by many manufacturing firms. In this paper, we consider a dual-channel green supply chain where one manufacturer produces a green product and sells it through one retail channel and its own direct channel. Consumers in the two channels have different perceptions of the product energy efficiency level due to different purchasing experiences. The product energy efficiency level evolves over time and is characterized as a dynamic variable. By developing and solving the Stackelberg differential game problems under the dynamic and static wholesale pricing strategies, respectively, we obtain the main results in this paper. First, the manufacturer has more incentives to invest in green innovation when more consumers buy the green product through the direct channel. Second, the manufacturer prefers to adopt the dynamic wholesale pricing strategy in most cases and prefers the static one only when the consumers in both channels have relatively high energy efficiency perceptions. By introducing the transfer payment contract, we show that the static wholesale pricing strategy may be the better choice, which leads to a win-win outcome for both members. Finally, sensitivity analysis further provides some managerial insights and verifies the robustness of the results.

\section{Introduction}

Environment has gradually become an important attention to many manufacturing firms and crucially impacted business performance [1]. With the large-scale development of manufacturing industry, governments around the world are facing increasingly severe environmental problems. With signing of many international environmental conventions (e.g., Kyoto Protocol, Montreal Convention, and Paris Agreement), more and more countries and regions are involved in the global environmental protection cooperation and actively develop emission reduction planning and encourage firms to implement green research and development policies. The Paris Agreement, as a legally binding climate agreement, clarifies the goal of controlling the global average temperature increase within this century to within two degrees Celsius, ultimately achieving sustainable human development. Sustainable development, regardless of developed or developing economies, enhances economic progression, social advancement, and environmental sustainability [2]. As a result, green supply chain management is becoming a hot topic and capturing keen scientific attention [3].

One of the most effective activities to develop a green supply chain is to design and produce environmentally friendly products [4]. Governments are making great efforts to guide firms to implement green innovation and improve consumer environmental awareness. For example, mandatory energy efficiency labels attached to household electrical appliances clearly present the information of energy consumption, which greatly promotes the adoption of high-efficiency appliances by consumers. An empirical survey demonstrates that $62 \%$ of consumers are willing to buy high-star appliances, and half of consumers are willing to pay $\$ 67.6$ more for purchasing air conditioners with a high energy efficiency level in India [5]. As announced by European Commission in 2008, three quarters of Europeans choose to purchase green products even though their prices are about 31\% higher than in 2005 [6]. The enhancement of public environmental awareness greatly affects firms' investment behaviors in green innovation [7]. Hence, it is very necessary for a profit-maximizing firm to make the 
optimal green investment decision, which is one of the main issues investigated in this paper.

Products with a high energy efficiency level not only reduce the energy consumption in usage for consumers, enhancing products' premium ability, but also present a good environmental image for firms, increasing firms' competitive advantage [8]. Recently, product upgrading has been the priority of many firms to develop green products with a high energy efficiency level. However, when firms invest in green innovation and produce energy-efficient products, they need to match new technologies, materials, equipment, manpower, and other resources, which often leads to a higher production cost and eventually a higher sales price than that of similar traditional products [4]. In general, firms would like to have a higher sales price with less investments in green innovation, while consumers expect to buy a product with a higher energy efficiency level at a lower price, which raises the opposition between firms and consumers [9]. Therefore, firms are faced with the important problem of how to balance the green innovation and pricing decisions.

The advanced e-commerce has made it easier for many green product manufacturers to develop their own online channels to directly sell their products to the end consumers, such as online sales websites http://www.sys2011.com and http://www.ehaier.com, in addition to selling through retail channels. This dual-channel mode has been widely used in various industries and is continuing to grow [10]. On the one hand, the online channel can greatly expand the consumer market by directly reaching some consumers who are far from a convenient retail store [11]. On the other hand, the establishment of the direct selling channel inevitably aggravates the channel conflict and competition between manufacturers and their downstream retailers. Moreover, a fact is that consumers in the two channels have different energy efficiency perceptions for the same green product, since the consumers in physical stores have the opportunity to check a green product carefully [12]. Consequently, firms need to consider the difference in energy efficiency perception of consumers in the two channels when making the green investment and operation decisions.

In addition, the degree of coordination between the supply chain members also affects the performance of the supply chain. Cachon [13] examined the wholesale pricing problem in a supply chain consisting of a supplier and a retailer and demonstrated that the supply chain's performance can be significantly improved through coordination. In practice, manufacturers may use static wholesale pricing, i.e., keep the same wholesale price all the time, or adopt dynamic wholesale pricing, i.e., adjust the wholesale price at any time. A reasonable wholesale pricing strategy can efficiently improve the economic and environmental performances of a supply chain and benefit both the supply chain members [14]. Considering cooperation and competition between a manufacturer and a retailer in such a dual-channel green supply chain, the wholesale pricing problem will be a valuable and interesting study.

Specifically, this paper aims to answer the following research questions:

Q1. What are the optimal pricing and investing decisions to maximize the profits of the members, and how do they interact with each other in the dualchannel green supply chain?

Q2. How do the dynamic and static wholesale pricing strategies affect the decision making and the profits of each member and the whole supply chain?

Q3. What are the interactions between green innovation and wholesale pricing?

To answer these questions, we consider a dual-channel green supply chain, where one manufacturer invests in green innovation and produces a green product and sells the product through a retail channel and its own direct channel. Considering that the energy efficiency standard changes with the development of technology, the energy efficiency level of the green product is described by a differential equation. Hence, the decision-making problem is modeled as a Stackelberg differential game in which the manufacturer acts as the leader and the retailer acts as the follower. With the dynamic or static wholesale pricing strategy, the dominant manufacturer firstly decides the dynamic or static wholesale price, the direct selling price, and the green innovation level, and then the retailer makes the retail price decision. According to the maximum principle, we obtain the equilibrium decisions and profits of the supply chain members under the two wholesale pricing strategies, respectively. Additionally, we conduct numerical studies to compare the outcomes under the two pricing strategies and provide sensitivity analysis with respect to key system parameters to obtain the main managerial implications.

The main contributions of this paper are summarized as follows. First, the energy efficiency level is modeled as a dynamic evolution process to reflect the reality in the green supply chain. Second, to examine the performance of the dualchannel green supply chain, this paper compares the dynamic and static wholesale pricing strategies for the first time. Third, the dominant parameter regions of the dynamic and static wholesale pricing strategies are described, respectively, which helps the supply chain members make the right decisions.

The rest of the paper is organized as follows. A review of the extant literature is presented in Section 2. In Section 3, we establish a Stackelberg differential game model. Section 4 and Section 5 examine the dynamic wholesale pricing strategy and the static wholesale pricing strategy, respectively. In Section 6, the effects of key system parameters are analysed, and the two pricing strategies are compared by numerical simulation. Section 7 concludes this paper.

\section{Literature Review}

Our study is related to the literature on green product, dualchannel green supply chain, and pricing strategy.

Environmental problem has become a rising concern around the world, and many researchers have engaged in the study of green products [3, 4, 9]. The literature of green product usually focuses on both economic and environmental benefits, which is closely related to the investment and operation activities of firms. Many firms improve the product's green level by investing in technology innovation [15] or introducing eco-labeling [16]. Noci and Verganti [17] 
showed that the improvement of social environmental awareness promotes more and more manufacturers to invest in green innovation and improve production. Chang and Fong [18] proposed the notions of green customer satisfaction and green customer loyalty, which provides a research framework to investigate green supply chains. Ramayah et al. [19] examined the effects of individual value and attitude on the purchase intention of a green product in a developing country. Jamali and Rasti-Barzoki [20] investigated the pricing and greening decisions of a green product competing with a nongreen product for market share. Considering stakeholders' environmental responsibilities, Hong and Guo [21] explored the environmental performance of several cooperation contracts in a green supply chain. Different from the above studies, our paper considers the energy efficiency level of a green product as a dynamic evolution process and focuses on investigating the performance of a dual-channel green supply chain.

The rapid development of e-commerce has provided a great opportunity for manufacturers to establish their own channels, and the dual-channel green product sales mode has been widely used in manufacturing industry. The effects of manufacturers developing direct channels on the green supply chain have been discussed in many studies $[10,11,22]$. Li et al. [12] studied the pricing and greening decisions in both centralized and decentralized cases of a dual-channel green supply chain. He et al. [23] analysed the effects of consumers' free riding and governmental e-commerce tax on carbon emissions in a dual-channel closed-loop supply chain. Based on a two-stage model, Basiri and Heydari [24] explored the coordination between a nongreen product channel and a substitutable green product channel. Chen et al. [25] considered the difference of environmental sustainability in different channels and discussed the effects of environmental sustainability on pricing policies in both centralized and decentralized models. Zhou et al. [26] studied the emission reduction behavior in a green supply chain with two cases of retail-channel and dualchannel and extended the problem to involve both cap-andtrade regulation and consumers' low-carbon preference. In the above studies, each green supply chain member may be better or worse off from adding the manufacturer's direct channel. When a product's green level is considered as a dynamic evolution process, what is the performance of the dual-channel supply chain? Different from the previous literature, this paper investigates the dynamic and static wholesale pricing strategies in a green dual-channel supply chain, which provides some insights into choosing pricing strategy.

Pricing is regarded as a tool for regulating operations and improving performance. The pricing mode generally includes static pricing and dynamic pricing based on whether prices change over time or not. Static pricing means that prices remain constant for a long period of time [27, 28]. Dynamic pricing means that prices change over time $[29,30]$. Some studies focus on the comparison between the two pricing strategies. For example, Cachon and Feldman [31] showed that facing strategic consumers, firms prefer to adopt static pricing rather than dynamic pricing. Zhang et al.
[32] examined the effects of static pricing and dynamic pricing on a supply chain and compared the results in different pricing modes. In our paper, we consider the dynamic energy efficiency level of a green product and focus on the comparison between dynamic wholesale pricing and static wholesale pricing in a dual-channel green supply chain.

Different from the above studies, our work extends the study of Shaorui et al. [33] to a dynamic scenario where the energy efficiency level is considered as a dynamic evolution process. This paper aims to investigate the wholesale pricing strategy in a dual-channel green supply chain. By formulating and solving the Stackelberg differential game problems, we obtain and compare the results of decisions and profits under the dynamic and static wholesale pricing strategies. We show the dominant parameter regions of the dynamic and static wholesale pricing strategies, respectively, which provides theoretical basis and management suggestions for the supply chain members to choose the optimal wholesale pricing strategy.

\section{The Model}

Consider a dual-channel green supply chain consisting of one manufacturer $(m)$ and one retailer $(r)$, where the manufacturer invests in green innovation and produces a green product for relieving the increasing environmental pressure. The manufacturer indirectly sells the product through the retailer with charging a wholesale price $w$ and also directly sells the product by developing a direct selling channel. Consumers can purchase the product from the traditional retail channel or the direct channel.

Following the previous literature $[34,35]$, a growing number of manufacturers have made heavy investments in $\mathrm{R} \& \mathrm{D}$ of green innovation for increasing the product's energy efficiency level to meet the social demand for environmental protection. The rapid development of technology allows the energy efficiency level to continuously improve, and thus it is more practical to characterize the level as a dynamic variable that depends on time [4]. Besides, the advancing technology also increases the energy efficiency standard, which means that a product's energy efficiency level degrades over time. For example, Minimum Energy Performance Standards (MEPS) are usually updated every $4-5$ years, increasing by about $10 \%$ over the previous level each time [36]. Thus, the product's energy efficiency level $\theta(t)$ is positively influenced by green innovation $u(t)$ but is subject to spontaneous decay due to the improvement of the energy efficiency standard over time. To capture the evolution of the energy efficiency level, the differential equation is introduced as follows:

$$
\begin{aligned}
& \dot{\theta}(t)=u(t)-k \theta(t), \\
& \theta(0)=\theta_{0},
\end{aligned}
$$

where $k>0$ is the decay coefficient of the energy efficiency level and $\theta_{0}$ denotes the initial energy efficiency level.

The manufacturer and the retailer, respectively, decide the direct selling price $p_{\mathrm{m}}$ and the retail price $p_{\mathrm{r}}$ for the product. $p_{\mathrm{m}}$ has a negative effect on the demand in the direct 
channel and has a positive effect on the demand in the retail channel, and for $p_{\mathrm{r}}$, vice versa. With the improvement of social environmental awareness, consumers prefer environmentally friendly products $[34,37]$. This means that a higher energy efficiency level will bring more demand. Thus, the demand $D_{\mathrm{r}}$ of the retail channel and the demand $D_{\mathrm{m}}$ of the direct channel, inspired by Zhang et al. [4], are given by

$$
\begin{aligned}
D_{\mathrm{r}} & =\phi a-p_{\mathrm{r}}+b p_{\mathrm{m}}+\beta_{\mathrm{r}} \theta, \\
D_{\mathrm{m}} & =(1-\phi) a-p_{\mathrm{m}}+b p_{\mathrm{r}}+\beta_{\mathrm{m}} \theta,
\end{aligned}
$$

where $a$ is a constant, representing the basic market size of the green product. $0 \leq b \leq 1$ is the price competition coefficient, reflecting the impact of the price in one channel on sales of its competitive channel. $0<\beta_{\mathrm{r}}<1$ and $0<\beta_{\mathrm{m}}<1$ represent the expansion effectiveness of the energy efficiency level to the demands in the retail channel and the direct channel, respectively. Since the consumers visiting a physical store can carefully check the green product, they have a higher energy efficiency perception than that in the direct channel, i.e., $\beta_{\mathrm{r}}>\beta_{\mathrm{m}} .0 \leq \phi \leq 1$ denotes the degree of consumer loyalty to the retail channel and is exogenous, and $1-\phi$ corresponds to the direct channel. This is a common assumption that the two channels share the total market demand in a dual-channel supply chain [38].

Although green innovation activities usually depend on the use of specific tools or machines, the adoption of such tools is considered as an instantaneous effort, and thus they do not affect the unit production cost of the green product [39]. According to a widely used form [40-42], the investment cost of green innovation is assumed to be convex and quadratic in green innovation level, i.e.,

$$
C(u)=\frac{1}{2} \eta u^{2},
$$

where $\eta>0$ is the cost efficiency. This assumption implies the marginally increasing cost of green innovation. In addition, to focus on our study, we normalize the production cost, the inventory-related costs, and the selling costs to be zero $[43,44]$.

Over an infinite planning horizon with the positive discount rate $\rho$, the objective functionals of the manufacturer and the retailer can be expressed as

$$
\begin{aligned}
J_{\mathrm{m}} & =\int_{0}^{\infty} e^{-\rho t}\left(w D_{\mathrm{r}}+p_{\mathrm{m}} D_{\mathrm{m}}-\frac{1}{2} \eta u^{2}\right) d t, \\
J_{\mathrm{r}} & =\int_{0}^{\infty} e^{-\rho t}\left(p_{\mathrm{r}}-w\right) D_{\mathrm{r}} d t .
\end{aligned}
$$

Considering that the energy efficiency level is a dynamic state, in the following sections, we explore two wholesale pricing strategies of the manufacturer: dynamic wholesale pricing strategy $(D)$ and static wholesale pricing strategy $(S)$. Specifically, we first derive the equilibrium decisions and profits of both members under the two pricing strategies and then compare these outcomes to obtain the main managerial implications by numerical simulation.

\section{Dynamic Wholesale Pricing Strategy $(D)$}

In this section, we discuss the scenario where the manufacturer provides a dynamic wholesale price to the downstream retailer. As in many theoretical and empirical studies $[10,28,45]$, the manufacturer and the retailer, respectively, act as the leader and the follower in a Stackelberg game. Specifically, the manufacturer first decides the green innovation level $u(t)$, the dynamic wholesale price $w(t)$, and the direct selling price $p_{\mathrm{m}}(t)$; then, based on the leader's decisions, the retailer determines the retail price $p_{\mathrm{r}}(t)$. The goals of both players are to maximize their respective profits.

The differential game problem between the two members is formulated as follows:

$$
\begin{array}{cl}
\max _{u(\cdot), w(\cdot), p_{\mathrm{m}}(\cdot)} & \int_{0}^{\infty} e^{-\rho t}\left(w(t) D_{\mathrm{r}}+p_{\mathrm{m}}(t) D_{\mathrm{m}}-\frac{1}{2} \eta u^{2}\right) d t \\
\max _{p_{\mathrm{r}}(\cdot)} & \int_{0}^{\infty} e^{-\rho t}\left(p_{\mathrm{r}}(t)-w(t)\right) D_{\mathrm{r}} d t \\
\text { s.t. } & \dot{\theta}(t)=u(t)-k \theta(t), \quad \theta(0)=\theta_{0} .
\end{array}
$$

Based on backward induction, we first identify the optimal retail price by solving the optimization problem of the retailer and then substitute the retailer's response function into the optimization problem of the manufacturer to recursively derive the optimal wholesale price, direct selling price, and green innovation level.

By solving the corresponding Hamilton-Jacobi-Bellman (HJB) equations for the dynamic optimization problems of the two members, we can obtain their feedback equilibria, which means that the pricing and green innovation decisions depend on the energy efficiency level. We use $V_{\mathrm{m}}^{\mathrm{D}}$ and $V_{\mathrm{r}}^{\mathrm{D}}$ as the value functions for the manufacturer and the retailer, respectively, where the superscript " $D$ " denotes the case with the dynamic wholesale pricing strategy. The HJB equations are given by

$$
\begin{aligned}
& \rho V_{\mathrm{m}}^{\mathrm{D}}= \max _{u(t), w(t), p_{\mathrm{m}}(t)}\left\{w(t) D_{\mathrm{r}}+p_{\mathrm{m}}(t) D_{\mathrm{m}}-\frac{1}{2} \eta u^{2}(t)\right. \\
&\left.+\frac{\partial V_{\mathrm{m}}^{\mathrm{D}}}{\partial \theta}(u(t)-k \theta(t))\right\}, \\
& \rho V_{\mathrm{r}}^{\mathrm{D}}=\max _{p_{\mathrm{r}}(t)}\left\{\left(p_{\mathrm{r}}(t)-w(t)\right) D_{\mathrm{r}}+\frac{\partial V_{\mathrm{r}}^{\mathrm{D}}}{\partial \theta}(u(t)-k \theta(t))\right\} .
\end{aligned}
$$

Proposition 1. With the dynamic wholesale pricing strategy, the equilibrium green innovation level, wholesale price, direct selling price, and retail price, respectively, are 


$$
\begin{aligned}
& u^{\mathrm{D}}(\theta)=\frac{m_{2}}{\eta}+\frac{2 m_{1}}{\eta} \theta \\
& w^{\mathrm{D}}(\theta)=\frac{a(b+\phi-b \phi)}{2-2 b^{2}}+\frac{\left(b \beta_{\mathrm{m}}+\beta_{\mathrm{r}}\right)}{2-2 b^{2}} \theta \\
& p_{\mathrm{m}}^{\mathrm{D}}(\theta)=\frac{a(b-1) \phi+a}{2-2 b^{2}}+\frac{\left(b \beta_{\mathrm{r}}+\beta_{\mathrm{m}}\right)}{2-2 b^{2}} \theta \\
& p_{\mathrm{r}}^{\mathrm{D}}(\theta)=\frac{a\left(b^{2} \phi+2 b(\phi-1)-3 \phi\right)}{4\left(b^{2}-1\right)}+\frac{\left(\left(b^{2}-3\right) \beta_{\mathrm{r}}-2 b \beta_{\mathrm{m}}\right)}{4\left(b^{2}-1\right)} \theta
\end{aligned}
$$

where

$$
\begin{aligned}
m_{1} & =\eta(\rho+2 k)-\frac{\xi}{4\left(1-b^{2}\right)}, \\
m_{2} & =\frac{a \eta\left(\left(b^{2} \phi-2 b(\phi-1)+\phi\right) \beta_{\mathrm{r}}+2((b-1) \phi+1) \beta_{\mathrm{m}}\right)}{4\left(1-b^{2}\right)\left(\eta(k+\rho)-2 m_{1}\right)}, \\
\xi & =\sqrt{\left(b^{2}-1\right) \eta\left(\left(b^{2}-1\right) \eta(2 k+\rho)^{2}+\left(b^{2}+1\right) \beta_{\mathrm{r}}^{2}+4 b \beta_{\mathrm{m}} \beta_{\mathrm{r}}+2 \beta_{\mathrm{m}}^{2}\right)} .
\end{aligned}
$$

By differentiating the feedback equilibrium green innovation level, wholesale price, and sales prices of the direct and retail channels to the energy efficiency level, we have $\left(\partial p_{r}^{D}(\theta) / \partial \theta\right)>\left(\partial w^{D}(\theta) / \partial \theta\right)>\left(\partial p_{\mathrm{m}}^{\mathrm{D}}(\theta) / \partial \theta\right)>0$. These inequalities, on the one hand, indicate that the energy efficiency level has positive effects on the wholesale price and sales prices, i.e., as the energy efficiency level increases, the manufacturer will set higher wholesale and direct selling prices and the retailer will raise the retail price; on the other hand, they show the fact that the effect of the energy efficiency level on the retail price is greater than that on the wholesale price which is stronger than that on the direct selling price. In addition, from $\partial u^{\mathrm{D}}(\theta) / \partial \theta>0$ for any value of $\theta$, it can be obtained that the manufacturer will make more investments in green innovation as the energy efficiency level increases.

Substituting equation (7) into equation (1) leads to the accumulated energy efficiency level over time, which is presented as follows.
Proposition 2. With the static wholesale pricing strategy, the path of the energy efficiency level over time is

$$
\theta^{\mathrm{D}}(t)=\theta_{\infty}^{\mathrm{D}}+\left(\theta_{0}-\theta_{\infty}^{\mathrm{D}}\right) e^{-B_{1} t},
$$

where

$$
\begin{aligned}
B_{1} & =\frac{\left(b^{2}-1\right) \eta \rho+\xi}{2\left(b^{2}-1\right) \eta}, \\
\theta_{\infty}^{\mathrm{D}} & =-\frac{a\left(b^{2}-1\right) \eta\left(\left(b^{2} \phi-2 b(\phi-1)+\phi\right) \beta_{\mathrm{r}}+2((b-1) \phi+1) \beta_{\mathrm{m}}\right)}{\left(\xi-\left(b^{2}-1\right) \eta \rho\right)\left(\left(b^{2}-1\right) \eta \rho+\xi\right)} .
\end{aligned}
$$

When $4\left(b^{2}-1\right) \eta k(k+\rho)+\left(b^{2}+1\right) \beta_{\mathrm{r}}^{2}+4 b \beta_{\mathrm{m}} \beta_{\mathrm{r}}+2 \beta_{\mathrm{m}}^{2}$ $>0, B_{1}>0$, and the energy efficiency level presented in equation (12) will converge to the steady state $\theta_{\infty}^{\mathrm{D}}$.

Substituting the equilibrium energy efficiency level $\theta^{\mathrm{D}}(t)$ into equations (7)-(10), we get the equilibrium green innovation level, wholesale price, and sales prices of the direct and retail channels.

Proposition 3. With the dynamic wholesale price strategy, the equilibrium green innovation level, wholesale price, direct selling price, and retail price paths over time, respectively, are

$$
\begin{aligned}
& u^{\mathrm{D}}(t)=u_{\mathrm{ss}}^{\mathrm{D}}+\frac{2 m_{1}}{\eta}\left(\theta_{0}-\theta_{\infty}^{\mathrm{D}}\right) e^{-B_{1} t}, \\
& w^{\mathrm{D}}(t)=w_{\mathrm{ss}}^{\mathrm{D}}+\frac{\left(b \beta_{\mathrm{m}}+\beta_{\mathrm{r}}\right)}{2-2 b^{2}}\left(\theta_{0}-\theta_{\infty}^{\mathrm{D}}\right) e^{-B_{1} t}, \\
& p_{\mathrm{m}}^{\mathrm{D}}(t)=p_{\mathrm{mss}}^{\mathrm{D}}+\frac{\left(b \beta_{\mathrm{r}}+\beta_{\mathrm{m}}\right)}{2-2 b^{2}}\left(\theta_{0}-\theta_{\infty}^{\mathrm{D}}\right) e^{-B_{1} t}, \\
& p_{\mathrm{r}}^{\mathrm{D}}(t)=p_{\mathrm{rss}}^{\mathrm{D}}+\frac{\left(\left(b^{2}-3\right) \beta_{\mathrm{r}}-2 b \beta_{\mathrm{m}}\right)}{4\left(b^{2}-1\right)}\left(\theta_{0}-\theta_{\infty}^{\mathrm{D}}\right) e^{-B_{1} t},
\end{aligned}
$$

where

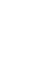

$$
\begin{aligned}
u_{\mathrm{ss}}^{\mathrm{D}} & =-\frac{a k\left(\left(b^{2} \phi-2 b(\phi-1)+\phi\right) \beta_{\mathrm{r}}+2((b-1) \phi+1) \beta_{\mathrm{m}}\right)}{4\left(b^{2}-1\right) \eta k(k+\rho)+\left(b^{2}+1\right) \beta_{\mathrm{r}}^{2}+4 b \beta_{\mathrm{m}} \beta_{\mathrm{r}}+2 \beta_{\mathrm{m}}^{2}}, \\
w_{\mathrm{ss}}^{\mathrm{D}} & =\frac{a\left(4 \eta k(b(\phi-1)-\phi)(k+\rho)+((b+2) \phi-2) \beta_{\mathrm{m}} \beta_{\mathrm{r}}+b(\phi-1) \beta_{\mathrm{r}}^{2}+2 \phi \beta_{\mathrm{m}}^{2}\right)}{2\left(4\left(b^{2}-1\right) \eta k(k+\rho)+\left(b^{2}+1\right) \beta_{\mathrm{r}}^{2}+4 b \beta_{\mathrm{m}} \beta_{\mathrm{r}}+2 \beta_{\mathrm{m}}^{2}\right)}, \\
p_{\mathrm{mss}}^{\mathrm{D}} & =-\frac{a\left(4 \eta k((b-1) \phi+1)(k+\rho)+\phi \beta_{\mathrm{m}} \beta_{\mathrm{r}}+(\phi-1) \beta_{\mathrm{r}}^{2}\right)}{2\left(4\left(b^{2}-1\right) \eta k(k+\rho)+\left(b^{2}+1\right) \beta_{\mathrm{r}}^{2}+4 b \beta_{\mathrm{m}} \beta_{\mathrm{r}}+2 \beta_{\mathrm{m}}^{2}\right)} \\
p_{\mathrm{rss}}^{\mathrm{D}} & =\frac{a\left(2 \eta k((b-1)(b+3) \phi-2 b)(k+\rho)+\left(2 b \beta_{\mathrm{r}}+3 \beta_{\mathrm{m}}\right)\left(\phi \beta_{\mathrm{m}}+(\phi-1) \beta_{\mathrm{r}}\right)\right)}{8\left(b^{2}-1\right) \eta k(k+\rho)+2\left(b^{2}+1\right) \beta_{\mathrm{r}}^{2}+8 b \beta_{\mathrm{m}} \beta_{\mathrm{r}}+4 \beta_{\mathrm{m}}^{2}} .
\end{aligned}
$$


By differentiating the steady states of green innovation level, wholesale price, and sales prices of the direct and retail channels to the key parameters, we can derive the following corollary.

Corollary 1. For the comparative statics of $w_{s s}^{D}, u_{s s}^{D}, p_{m s s}^{D}$, and $p_{r s s}^{D}$ with respect to key parameters $\phi, \rho$, and $k$, we have the following:

(1) $\left(\partial u_{\mathrm{ss}}^{\mathrm{D}} / \partial \phi\right)<0,\left(\partial w_{\mathrm{ss}}^{\mathrm{D}} / \partial \phi\right)>0,\left(\partial p_{\mathrm{mss}}^{\mathrm{D}} / \partial \phi\right)<0,\left(\partial p_{\mathrm{rss}}^{\mathrm{D}} /\right.$ $\partial \phi)>0$

(2) $\left(\partial u_{\mathrm{ss}}^{\mathrm{D}} / \partial \rho\right)<0, \quad\left(\partial w_{\mathrm{ss}}^{\mathrm{D}} / \partial \rho\right)<0, \quad\left(\partial p_{\mathrm{mss}}^{\mathrm{D}} / \partial \rho\right)<0, \quad\left(\partial p_{\mathrm{rss}}^{\mathrm{D}} /\right.$ $\partial \rho)<0$

(3) $\left(\partial u_{\mathrm{ss}}^{\mathrm{D}} / \partial k\right)<0,\left(\partial w_{\mathrm{ss}}^{\mathrm{D}} / \partial k\right)<0,\left(\partial p_{\mathrm{mss}}^{\mathrm{D}} / \partial k\right)<0,\left(\partial p_{\mathrm{rss}}^{\mathrm{D}} /\right.$ $\partial k)<0$

The results in Corollary 1 (1) show that when the number of consumers in the direct channel increases, the manufacturer prefers to invest more in green innovation and provides a higher direct selling price; as more consumers visit the retail store, the manufacturer will charge a higher wholesale price and the retailer will set a higher retail price. From Corollary 1 (2), we can obtain that as the discount rate decreases, the manufacturer's future earnings will increase significantly, which promotes the manufacturer to invest more in green innovation, and thus the manufacturer charges a higher wholesale price and sets a higher direct selling price; as a response, the retailer will set a higher retail price. It can be seen from Corollary 1 (3) that when the decay coefficient of the energy efficiency level is low, there will be more investments in green innovation, higher wholesale price, and higher sales prices.

According to equations (14)-(17), we describe two pricing strategies: skimming pricing and penetration pricing, which are distinguished based on the relationship between $\theta_{0}$ and $\theta_{\infty}^{\mathrm{D}}$ and are illustrated as follows.

Corollary 2. With the dynamic wholesale pricing strategy, we have the following:

(1) If $\theta_{0}>\theta_{\infty}^{\mathrm{D}}$, the wholesale price and the sales prices decrease with time, both the supply chain members take skimming pricing

(2) If $\theta_{0}<\theta_{\infty}^{\mathrm{D}}$, the wholesale price and the sales prices increase with time, both the supply chain members take penetration pricing

(3) If $\theta_{0}=\theta_{\infty}^{\mathrm{D}}$, the wholesale price and the sales prices are constant over the planning time

The above corollary shows that when the steady energy efficiency level is lower than the initial energy efficiency level, the pricing trajectories are monotonically increasing with time. The intuition is that if the initial energy efficiency level is sufficiently high, the manufacturer will gradually reduce the green innovation investment, which leads to decreased energy efficiency level. As a result, the number of consumers both in the direct and retail channels becomes less, which prompts the manufacturer to adopt a low price strategy to boost consumption and provide a lower wholesale price to maintain a good business relationship with the retailer.

With the equilibrium decisions under the dynamic wholesale pricing strategy, the profits of the manufacture and the retailer are given by

$$
\begin{gathered}
J_{\mathrm{m}}^{\mathrm{D}}=m_{1} \theta_{0}^{2}+m_{2} \theta_{0}+m_{3}, \\
J_{\mathrm{r}}^{\mathrm{D}}=n_{1} \theta_{0}^{2}+n_{2} \theta_{0}+n_{3},
\end{gathered}
$$

where

$$
\begin{aligned}
& m_{3}=\frac{4\left(b^{2}-1\right) m_{2}^{2}-a^{2} \eta((b-1) \phi((b-3) \phi+4)+2)}{8\left(b^{2}-1\right) \eta \rho}, \\
& n_{1}=\frac{\left(1-b^{2}\right) \eta \beta_{\mathrm{r}}^{2}}{16 \xi}, \\
& n_{2}=\frac{a \eta\left(\left(b^{2}-1\right) \phi \beta_{\mathrm{r}}\left(\eta(k+\rho)-2 m_{1}\right)-4 n_{1}\left(\left(b^{2} \phi-2 b(\phi-1)+\phi\right) \beta_{\mathrm{r}}+2((b-1) \phi+1) \beta_{\mathrm{m}}\right)\right)}{8\left(b^{2}-1\right)\left(\eta(k+\rho)-2 m_{1}\right)^{2}}, \\
& n_{3}=\frac{a^{2} \eta \phi^{2}+16 m_{2} n_{2}}{16 \rho \eta} .
\end{aligned}
$$

\section{Static Wholesale Pricing Strategy $(S)$}

In this section, we consider the case where the manufacturer and the retailer trade through a static wholesale price. In this scenario, the manufacturer commits a reasonable wholesale price at the beginning of the selling season and keeps it for a long time.
Similar to the dynamic wholesale pricing problem, the static one is also a Stackelberg differential game, and the sequence of the game is as follows. The manufacturer first commits the static wholesale price $w$ and then decides the green innovation level $u(t)$ and the direct selling price $p_{\mathrm{m}}(t)$. Based on these decisions, the retailer determines the retail price $p_{\mathrm{r}}(t)$. 
The differential game problem between the members can be formulated as follows:

$$
\begin{array}{ll}
\max _{w, u(\cdot), p_{\mathrm{m}}(\cdot)} & \int_{0}^{\infty} e^{-\rho t}\left(w D_{\mathrm{r}}+p_{\mathrm{m}}(t) D_{\mathrm{m}}-\frac{1}{2} \eta u^{2}\right) d t \\
\max _{p_{\mathrm{r}}(\cdot)} & \int_{0}^{\infty} e^{-\rho t}\left(p_{\mathrm{r}}(t)-w\right) D_{\mathrm{r}} d t \\
\text { s.t. } & \dot{\theta}(t)=u(t)-k \theta(t), \quad \theta(0)=\theta_{0} .
\end{array}
$$

According to backward induction, we first solve the retailer's optimization problem to determine the optimal retail price. Then, by substituting the retailer's response function into the manufacturer's problem, the optimal direct selling price and green innovation level are recursively derived. Finally, the optimal wholesale price is identified to maximize the manufacturer's profit. We use $V_{\mathrm{m}}^{\mathrm{S}}$ and $V_{\mathrm{r}}^{\mathrm{S}}$ to denote the value functions of the manufacturer and the retailer, respectively, in the static wholesale pricing case. The $\mathrm{HJB}$ equations are given by

$$
\begin{aligned}
\rho V_{\mathrm{m}}^{\mathrm{S}}= & \max _{p_{\mathrm{m}}(t), w, u(t)}\left\{w D_{\mathrm{r}}+p_{\mathrm{m}}(t) D_{\mathrm{m}}-\frac{1}{2} \eta u^{2}(t)\right. \\
& \left.+\frac{\partial V_{\mathrm{m}}^{\mathrm{D}}}{\partial \theta}(u(t)-k \theta(t))\right\}, \\
\rho V_{\mathrm{r}}^{\mathrm{S}}= & \max _{p_{\mathrm{r}}(t)}\left\{\left(p_{\mathrm{r}}(t)-w\right) D_{\mathrm{r}}+\frac{\partial V_{\mathrm{r}}^{\mathrm{D}}}{\partial \theta}(u(t)-k \theta(t))\right\} .
\end{aligned}
$$

The feedback equilibrium decisions of the manufacturer and the retailer can be obtained and presented as follows.

Proposition 4. With the static wholesale pricing strategy, the equilibrium wholesale price, green innovation level, and sales prices, respectively, are

$$
\begin{aligned}
w^{\mathrm{S}}= & \frac{1}{2 A_{1}-4 A_{2}}\left(2 \beta_{\mathrm{m}}\left(a\left(b^{2}-2\right) \phi \beta_{\mathrm{m}}+b \theta_{0} \rho\left(\tau-\left(b^{2}-2\right) \eta \rho\right)\right)\right. \\
& +\beta_{\mathrm{r}}\left(a\left(b^{2}-2\right)((b+2) \phi-2) \beta_{\mathrm{m}}+2 \theta_{0} \rho\left(\tau-\left(b^{2}-2\right) \eta \rho\right)\right) \\
& +2 a(b(\phi-1)-\phi)\left(\left(b^{2}-2\right) \eta\left(2 k^{2}+2 k \rho+\rho^{2}-\rho \tau\right)\right) \\
& \left.+a b\left(b^{2}-2\right)(\phi-1) \beta_{\mathrm{r}}^{2}\right), \\
u^{\mathrm{S}}(\theta)= & \frac{l_{2}}{\eta}+\frac{2 l_{1}}{\eta} \theta, \\
p_{\mathrm{m}}^{\mathrm{S}}(\theta)= & \frac{2\left(a+b w^{\mathrm{S}}\right)+a(b-2) \phi}{4-2 b^{2}}+\frac{\left(b \beta_{\mathrm{r}}+2 \beta_{\mathrm{m}}\right)}{4-2 b^{2}} \theta, \\
p_{\mathrm{r}}^{\mathrm{S}}(\theta)= & \frac{1}{2}\left(\frac{2 b\left(a+b w^{\mathrm{S}}\right)+a(b-2) b \phi}{4-2 b^{2}}+a \phi+w\right) \\
& +\frac{1}{2}\left(\frac{2 b \beta_{\mathrm{m}}+b^{2} \beta_{\mathrm{r}}}{4-2 b^{2}}+\beta_{\mathrm{r}}\right) \theta,
\end{aligned}
$$

where

$$
\begin{aligned}
A_{1} & =\left(b^{2}-2\right)\left(\left(b^{2}+1\right) \beta_{\mathrm{r}}^{2}+4 b \beta_{\mathrm{m}} \beta_{\mathrm{r}}+2 \beta_{\mathrm{m}}^{2}\right), \\
A_{2} & =\left(b^{2}-1\right) \rho \tau+2\left(b^{4}-3 b^{2}+2\right) \eta\left(2 k^{2}+2 k \rho+\rho^{2}\right), \\
\tau & =\sqrt{\left(b^{2}-2\right) \eta\left(\left(b^{2}-2\right) \eta(2 k+\rho)^{2}+b^{2} \beta_{\mathrm{r}}^{2}+4 b \beta_{\mathrm{m}} \beta_{\mathrm{r}}+4 \beta_{\mathrm{m}}^{2}\right)}, \\
l_{1} & =\frac{b^{2} \eta \rho+2 b^{2} \eta k+\tau-2 \eta \rho-4 \eta k}{4\left(b^{2}-2\right)}, \\
l_{2} & =-\frac{\eta\left(2 \beta_{\mathrm{m}}(a((b-2) \phi+2)+2 b w)+\beta_{\mathrm{r}}(a b((b-2) \phi+2)+4 w)\right)}{4\left(b^{2}-2\right)\left(\eta(k+\rho)-2 m_{1}\right)} .
\end{aligned}
$$

Substituting equation (20) into equation (1), we can obtain the accumulated energy efficiency level over time, which is described in the following proposition.

Proposition 5. With the static wholesale pricing strategy, the path of the energy efficiency level over time is

$$
\theta^{S}(t)=\theta_{\infty}^{S}+\left(\theta_{0}-\theta_{\infty}^{S}\right) e^{-B_{2} t},
$$

where

$$
\begin{aligned}
B_{2} & =\frac{4\left(2-b^{2}\right) \eta k(k+\rho)-b^{2} \beta_{\mathrm{r}}^{2}-4 b \beta_{\mathrm{m}} \beta_{\mathrm{r}}-4 \beta_{\mathrm{m}}^{2}}{2\left(b^{2}(-\eta) \rho-\omega+2 \eta \rho\right)}, \\
\theta_{\infty}^{\mathrm{S}} & =\frac{2 \beta_{\mathrm{m}}(a((b-2) \phi+2)+2 b w)+\beta_{\mathrm{r}}(a b((b-2) \phi+2)+4 w)}{4\left(2-b^{2}\right) \eta k(k+\rho)-b^{2} \beta_{\mathrm{r}}^{2}-4 b \beta_{\mathrm{m}} \beta_{\mathrm{r}}-4 \beta_{\mathrm{m}}^{2}} .
\end{aligned}
$$

When $\quad 4\left(2-b^{2}\right) \eta k(k+\rho)-b^{2} \beta_{\mathrm{r}}^{2}-4 b \beta_{\mathrm{m}} \beta_{\mathrm{r}}-4 \beta_{\mathrm{m}}^{2}>0$, $B_{2}>0$, and the energy efficiency level presented in equation (24) will converge to the steady state $\theta_{\infty}^{\mathrm{S}}$.

Similar to the dynamic wholesale pricing case, based on the gap of $\theta_{0}$ and $\theta_{\infty}^{\mathrm{S}}$, both the supply chain members choose the skimming pricing or the penetration pricing.

\section{Numerical Study}

Despite having derived the analytical results of the equilibrium decisions and profits, it is difficult to further obtain managerial insights analytically due to the complexity of expressions. In this section, we conduct extensive numerical examples to demonstrate the robustness of the results and obtain the effects of key system parameters on the green supply chain and numerically compare the two strategies to obtain main managerial implications.

The basic parameters are set as follows:

Demand parameters: $a=20, b=0.1, \beta_{\mathrm{m}}=0.9$, and $\beta_{\mathrm{r}}=0.7$

Energy efficiency parameters: $k=0.9$ and $\theta_{0}=10$

Profit parameters: $\phi=0.1, \rho=0.5$, and $\eta=1$

These parameters are selected based on previous studies on the green supply chain $[4,12]$. 
6.1. Sensitivity Analysis. The preferences for wholesale pricing of the supply chain members are affected by some key system parameters: the degree of customer loyalty to the retail channel $(\phi)$, the price competition intensity between the direct and retail channels $(b)$, the decay coefficient $(k)$, the green innovation cost parameter $(\eta)$, and the discount rate $(\rho)$.

We focus on the steady states of decision variables in this study. Tables 1 and 2 report the effects of the main parameters on the long-term decision-making behaviors and profits of the supply chain members under the dynamic and static wholesale pricing strategies, respectively. The results of sensitivity analysis are summarized as follows.

A larger discount rate $\rho$ leads to lower steady-state wholesale price, sales prices, green innovation level, and profits under the two pricing strategies. From an economic point of view, the larger discount rate indicates that the decision makers are less patient. It is intuitive that a less patient manufacturer has more motivation to cut the wholesale price and the direct selling price to stimulate demand rather than increase the green innovation investments. This also makes the retailer reduce the retail price to maximize his own profit. With the discount rate gradually becoming larger, the product demand in the retail and direct channels would be smaller, since the negative effect of the reduced energy efficiency level dominates the positive effect of decreasing the sales prices on the demands. Therefore, regardless of the wholesale pricing mode, the profits of each member and the whole supply chain are reduced.

The degree of consumer loyalty to the retail channel positively affects the steady-state wholesale price, retail price, and profit of the retailer, while negatively affects the steadystate direct selling price, green innovation, and profits of the manufacturer and the whole supply chain. A higher $\phi$ means that the consumers are inclined to buy products from the retail channel, and the purchase amount in the direct channel is reduced. When there is a higher $\phi$, the retailer has more incentives to grab higher profit via a high retail price. Aiming at competing with the retail channel and maintaining a suitable profit level in the direct channel, the manufacturer is motivated to increase the wholesale price and cut the direct selling price. As a result, the manufacturer obtains a lower profit and thus invests less in green innovation under each wholesale pricing strategy.

With the substitutability parameter $b$ increasing, the steady-state wholesale price, retail and direct selling prices, green innovation level, and profits of each member and the whole supply chain under each wholesale pricing strategy increase. A higher $b$ implies that the demands are expanded in both channels, and the members have incentives to choose higher prices. The manufacturer invests more in green innovation for building up a higher energy efficiency level. Regardless of the wholesale pricing mode, the profits of both members and the whole supply chain will increase as the market demands and prices increase.

It can be also found that the decay coefficient $k$ of energy efficiency level negatively affects the steady-state wholesale price, sales prices, green innovation, and profits of both members and the whole supply chain. As $k$ increases, the manufacturer has less incentives to invest in green innovation, and thus both members have to cut the prices for retaining consumers. As a result of shrinking market demands and reduced sales prices, the profits of both members decrease. In addition, it is intuitive that the increased green innovation cost parameter $\eta$ has similarly negative effects with the decay coefficient $k$ on the green supply chain.

6.2. Comparison of Two Wholesale Pricing Strategies. In this section, we compare the dynamic and static wholesale pricing strategies. To easily present the comparison results, we use $\Delta w, \Delta p_{\mathrm{r}}, \Delta p_{\mathrm{m}}$, and $\Delta u$ to denote the differences of the steady-state wholesale price, retail price, direct selling price, and green innovation level between the two pricing strategies, respectively. The differences of the profits of the whole supply chain, the manufacturer, and the retailer between the two pricing strategies are denoted by $\Delta J, \Delta J_{\mathrm{m}}$, and $\Delta J_{\mathrm{r}}$, respectively. We carry out extensive numerical studies to obtain more managerial implications. The comparison results concerning the steady-state wholesale price, sales prices, green innovation level, and profits of each member and the whole supply chain between the two wholesale pricing strategies are shown in Figures 1-8.

From Figures 1-8, we can find that the profit of the manufacturer with the dynamic wholesale pricing strategy is always higher than that with the static pricing strategy, i.e., $\pi_{\mathrm{m}}^{* \mathrm{D}}>\pi_{\mathrm{m}}^{* \mathrm{~S}}$. In general, since the dynamic strategy has more flexibility and timeliness than the static strategy in pricing adjustment, the manufacturer will reach a higher profit with adopting the dynamic wholesale pricing strategy as compared to the static wholesale pricing strategy.

Specifically, it can be seen from Figure 1 that as the degree of the consumer loyalty to the retail channel $\phi$ increases, $\Delta w$ gradually changes from positive to negative. This demonstrates that the wholesale price under the dynamic pricing strategy is higher than the static one when $\phi$ is small, and the former is lower than the latter when $\phi$ is large, with the threshold $\phi=0.21$. Also, with the increase of parameter $\phi$, the sales prices and the green innovation level have the similar trends with the wholesale price. It should be noted that for a larger $\phi$, the manufacturer prefers to invest less in green innovation with the dynamic pricing strategy than that with static one, which is in consistent with the conclusions in Zhang et al. [4]. According to Figure 2, we can find that the differences of the profits of the retailer and the whole supply chain between the two wholesale pricing strategies, $\Delta J_{\mathrm{r}}$ and $\Delta J$, gradually change from positive to negative as $\phi$ increases, while the difference of the manufacturer's profit $\Delta J_{\mathrm{m}} \geq 0$. Moreover, we find that in Figure 2, the threshold of $\phi$ is also 0.21 . Specifically, when $\phi>0.21$, if the manufacturer adopts the static pricing strategy, the profits of the retailer and the whole supply chain are always higher than that in the dynamic case, i.e., $J_{\mathrm{r}}^{* \mathrm{~S}}>J_{\mathrm{r}}^{* \mathrm{D}}$ and $J^{* \mathrm{~S}}>J^{* \mathrm{D}}$. There is an interesting finding that the efficiency of the whole supply chain is improved with a static wholesale price, but the manufacturer has a loss of profit.

Once the profit decreases, the manufacturer will inevitably reduce the initiative to adopt the static pricing strategy. For this, the transfer payment contract (the profit distribution of the supply chain members) can be given by 
TABLE 1: Steady-state decisions and profits under dynamic pricing.

\begin{tabular}{|c|c|c|c|c|c|c|c|c|}
\hline \multicolumn{2}{|c|}{ Parameter } & $p_{\mathrm{m}}^{* \mathrm{D}}$ & $w^{* \mathrm{D}}$ & $u^{* \mathrm{D}}$ & $p_{\mathrm{r}}^{* \mathrm{D}}$ & $\pi_{\mathrm{m}}^{* \mathrm{D}}$ & $\pi_{\mathrm{r}}^{* \mathrm{D}}$ & $\pi^{* \mathrm{D}}$ \\
\hline \multicolumn{2}{|c|}{ Benchmark } & 13.337 & 7.009 & 9.350 & 9.846 & 293.359 & 15.674 & 309.033 \\
\hline \multirow{4}{*}{$\rho$} & 0.10 & 17.240 & 11.801 & 18.155 & 16.840 & 1634.740 & 223.695 & 1858.440 \\
\hline & 0.30 & 14.664 & 8.638 & 12.343 & 12.224 & 497.515 & 36.763 & 534.278 \\
\hline & 0.70 & 12.528 & 6.015 & 7.525 & 8.397 & 210.363 & 9.447 & 219.810 \\
\hline & 0.90 & 11.983 & 5.347 & 6.296 & 7.421 & 165.345 & 6.741 & 172.085 \\
\hline \multirow{4}{*}{$\phi$} & 0.05 & 13.864 & 6.643 & 9.513 & 9.271 & 312.318 & 13.236 & 325.554 \\
\hline & 0.15 & 12.810 & 7.375 & 9.187 & 10.422 & 275.745 & 18.319 & 294.064 \\
\hline & 0.20 & 12.284 & 7.741 & 9.025 & 10.997 & 259.478 & 21.171 & 280.648 \\
\hline & 0.25 & 11.757 & 8.107 & 8.862 & 11.572 & 244.555 & 24.229 & 268.784 \\
\hline \multirow{4}{*}{$k$} & 0.75 & 16.521 & 10.919 & 13.778 & 15.552 & 331.885 & 27.010 & 358.895 \\
\hline & 0.80 & 15.083 & 9.152 & 11.812 & 12.975 & 316.310 & 21.892 & 338.202 \\
\hline & 0.85 & 14.077 & 7.918 & 10.408 & 11.173 & 303.752 & 18.305 & 322.058 \\
\hline & 0.95 & 12.771 & 6.313 & 8.521 & 8.831 & 284.582 & 13.674 & 298.256 \\
\hline \multirow{4}{*}{$b$} & 0.05 & 12.527 & 5.789 & 8.326 & 8.371 & 276.719 & 14.089 & 290.808 \\
\hline & 0.15 & 14.398 & 8.467 & 10.615 & 11.621 & 313.787 & 17.719 & 331.506 \\
\hline & 0.20 & 15.807 & 10.272 & 12.222 & 13.828 & 339.144 & 20.442 & 359.586 \\
\hline & 0.25 & 17.726 & 12.600 & 14.337 & 16.684 & 371.162 & 24.218 & 395.381 \\
\hline \multirow{4}{*}{$\eta$} & 0.60 & 22.104 & 17.773 & 29.125 & 25.554 & 380.649 & 55.389 & 436.038 \\
\hline & 0.80 & 15.467 & 9.625 & 14.156 & 13.663 & 318.079 & 23.922 & 342.001 \\
\hline & 1.20 & 12.286 & 5.719 & 6.980 & 7.964 & 280.006 & 12.115 & 292.121 \\
\hline & 1.40 & 11.661 & 4.951 & 5.569 & 6.843 & 271.622 & 10.186 & 281.808 \\
\hline
\end{tabular}

TABLe 2: Steady-state decisions and profits under static pricing.

\begin{tabular}{|c|c|c|c|c|c|c|c|c|}
\hline \multicolumn{2}{|c|}{ Parameter } & $p_{\mathrm{m}}^{* \mathrm{~S}}$ & $w^{* S}$ & $u^{* S}$ & $p_{\mathrm{r}}^{* \mathrm{~S}}$ & $\pi_{\mathrm{m}}^{* \mathrm{~S}}$ & $\pi_{\mathrm{r}}^{* \mathrm{~S}}$ & $\pi^{* \mathrm{~S}}$ \\
\hline \multicolumn{2}{|c|}{ Benchmark } & 13.316 & 6.921 & 9.311 & & & & \\
\hline \multirow{4}{*}{$\rho$} & 0.10 & 16.932 & 10.904 & 17.521 & 16.059 & 1628.630 & 223.720 & 1852.350 \\
\hline & 0.30 & 14.481 & 7.982 & 11.984 & 11.707 & 497.092 & 36.638 & 533.730 \\
\hline & 0.70 & 12.616 & 6.440 & 7.686 & 8.694 & 210.329 & 9.541 & 219.870 \\
\hline & 0.90 & 12.142 & 6.200 & 6.576 & 7.995 & 165.262 & 6.899 & 172.161 \\
\hline \multirow{4}{*}{$\phi$} & 0.05 & 13.833 & 6.514 & 9.455 & 9.176 & 312.311 & 13.210 & 325.521 \\
\hline & 0.15 & 12.799 & 7.328 & 9.166 & 10.387 & 275.745 & 18.305 & 294.050 \\
\hline & 0.20 & 12.282 & 7.735 & 9.022 & 10.992 & 259.478 & 21.169 & 280.646 \\
\hline & 0.25 & 11.765 & 8.141 & 8.878 & 11.598 & 244.555 & 24.242 & 268.796 \\
\hline \multirow{4}{*}{$k$} & 0.75 & 15.760 & 8.594 & 12.487 & 13.577 & 330.781 & 27.126 & 357.907 \\
\hline & 0.80 & 14.727 & 7.925 & 11.183 & 11.990 & 315.920 & 21.855 & 337.775 \\
\hline & 0.85 & 13.937 & 7.378 & 10.150 & 10.760 & 303.661 & 18.234 & 321.894 \\
\hline & 0.95 & 12.818 & 6.533 & 8.613 & 8.988 & 284.561 & 13.754 & 298.315 \\
\hline \multirow{4}{*}{$b$} & 0.05 & 12.558 & 5.948 & 8.393 & 8.484 & 276.709 & 14.142 & 290.851 \\
\hline & 0.15 & 14.275 & 8.030 & 10.407 & 11.289 & 313.722 & 17.653 & 331.375 \\
\hline & 0.20 & 15.495 & 9.324 & 11.741 & 13.082 & 338.867 & 20.392 & 359.259 \\
\hline & 0.25 & 17.066 & 10.873 & 13.399 & 15.269 & 370.354 & 24.295 & 394.649 \\
\hline \multirow{4}{*}{$\eta$} & 0.60 & 19.274 & 11.234 & 23.113 & 19.137 & 373.730 & 55.302 & 429.031 \\
\hline & 0.80 & 15.044 & 8.215 & 13.308 & 12.514 & 317.504 & 23.910 & 341.414 \\
\hline & 1.20 & 12.382 & 6.201 & 7.152 & 8.295 & 279.907 & 12.334 & 292.241 \\
\hline & 1.40 & 11.798 & 5.742 & 5.803 & 7.362 & 271.332 & 10.677 & 282.009 \\
\hline
\end{tabular}

$$
\begin{aligned}
& J_{\mathrm{m}}=J_{\mathrm{m}}^{\mathrm{D}}-\mu \Delta J, \\
& J_{\mathrm{r}}=J_{\mathrm{r}}^{\mathrm{D}}-(1-\mu) \Delta J,
\end{aligned}
$$

where $0<\mu<1$ is the distribution ratio of the difference of the profit of the whole supply chain between the two pricing strategies, which can be determined by negotiation between the manufacturer and the retailer. The transfer payment contract allows the manufacturer to receive a certain amount of compensation, which addresses the problem of insufficient incentives for the manufacturer to adopt static pricing. Figure 2 shows that when $\phi>0.21, \Delta J<0$, which implies that the supply chain has higher operating efficiency when adopting static pricing compared with dynamic pricing. Hence, with the transfer payment contract, the manufacturer is motivated to adopt static pricing, and this leads to higher profits of both members as compared with the dynamic one, which results in a win-win outcome for both members.

As mentioned above, when a large number of consumers prefer to buy goods from the direct channel, the dynamic wholesale pricing strategy makes the supply chain more efficient than the static one. However, when more and more consumers turn to the physical store, the static wholesale pricing strategy combined with the transfer payment contract 


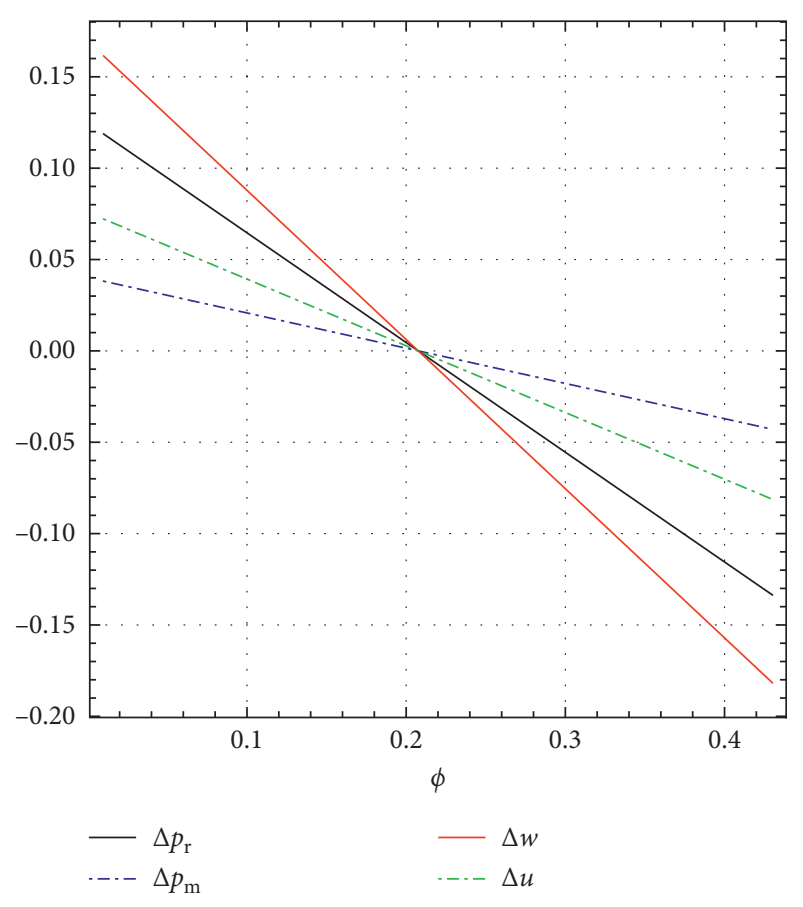

FIGURE 1: Comparison of steady-state decisions with $\phi$.

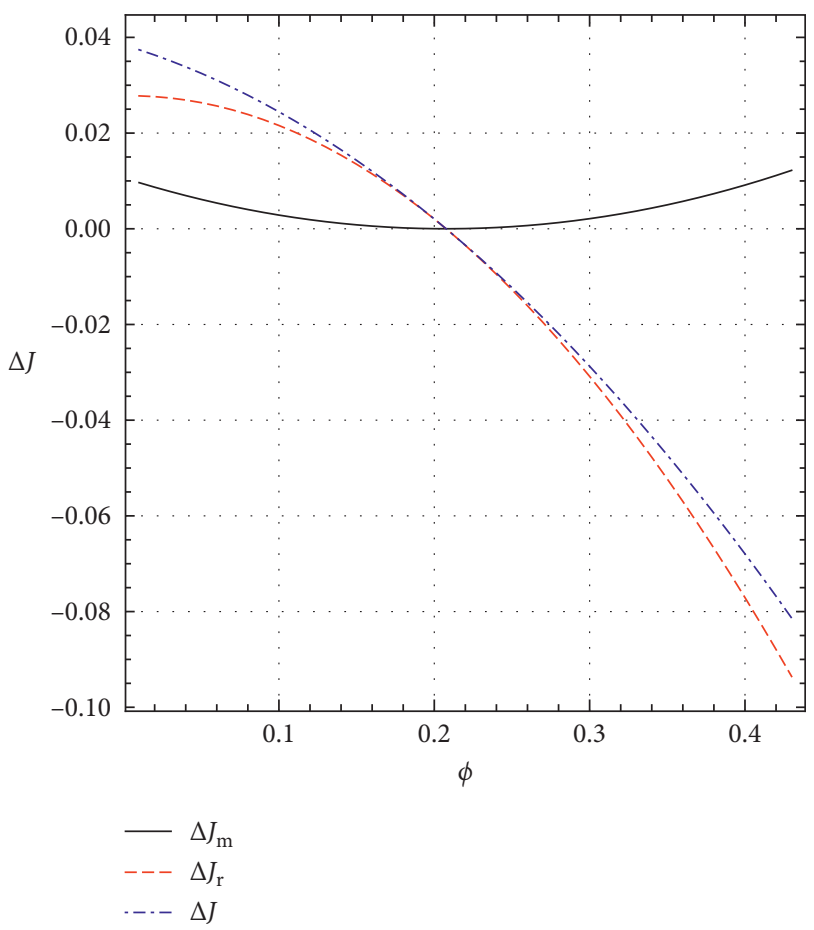

Figure 2: Comparison of steady-state profits with $\phi$.

will be the better one. Note that in practice, the manufacturer usually incurs the cost of adjusting the wholesale price if adopting dynamic pricing, which can be found in [46]. Moreover, there are some negative effects of adjusting the wholesale price frequently, such as damaging the commercial

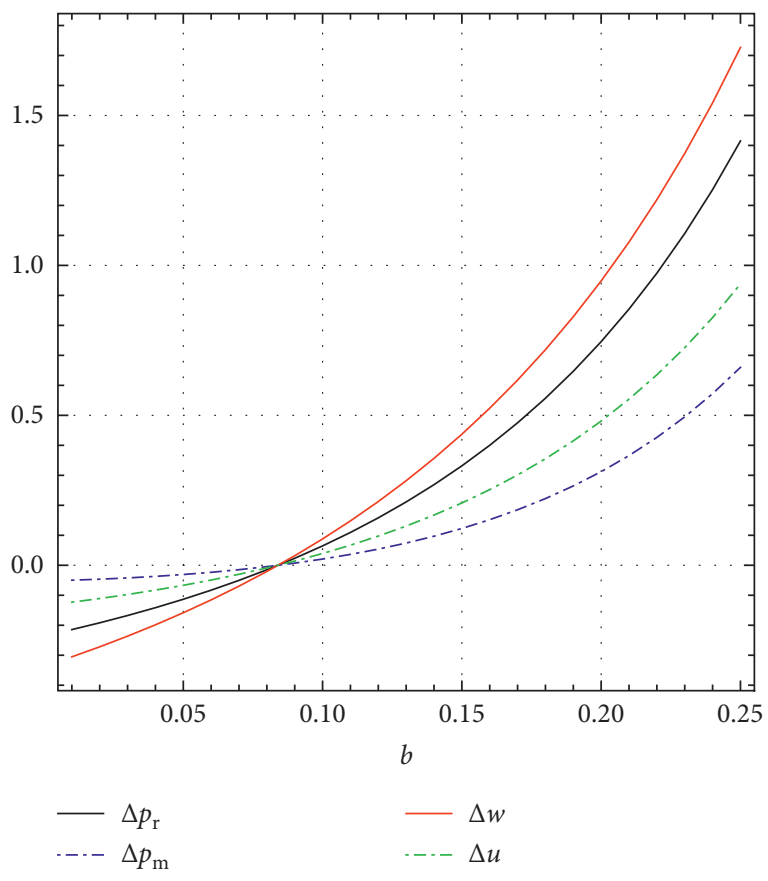

Figure 3: Comparison of steady-state decisions with $b$.

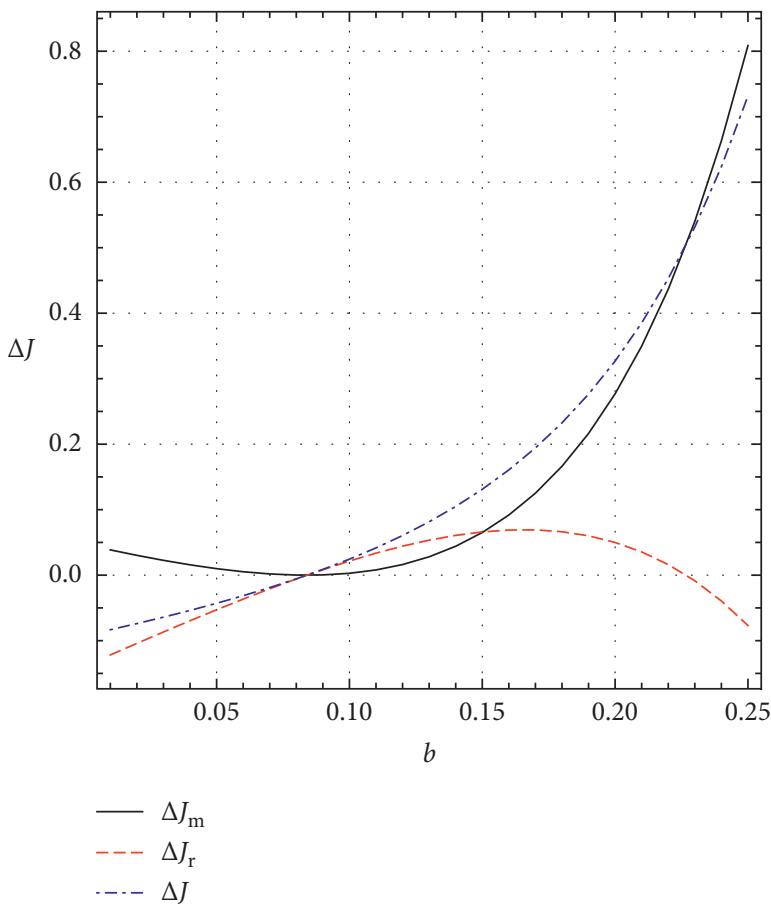

FIgURE 4: Comparison of steady-state profits with $b$.

relationship between the manufacturer and the retailer and hurting the goodwill of the manufacturer. Therefore, the manufacturer has to weigh the pros and cons of dynamically adjusting the wholesale price. From this point of view, the static pricing strategy may be the better choice for the manufacturer.

As presented in Figure 3, the differences of the wholesale price, sales price, and green innovation level between the two pricing strategies change from negative to positive with the 

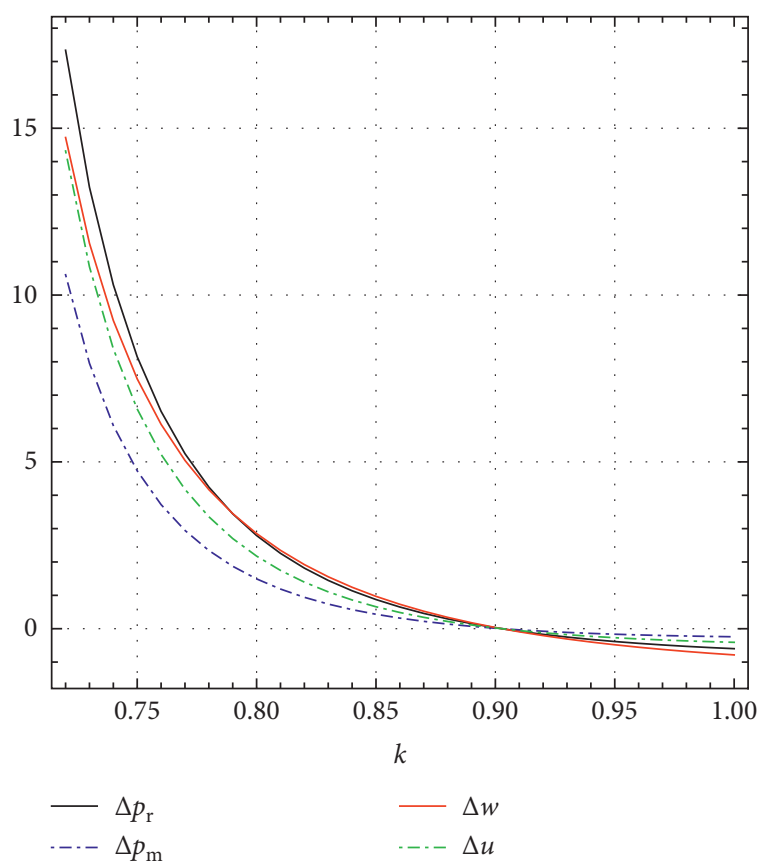

Figure 5: Comparison of steady-state decisions with $k$.

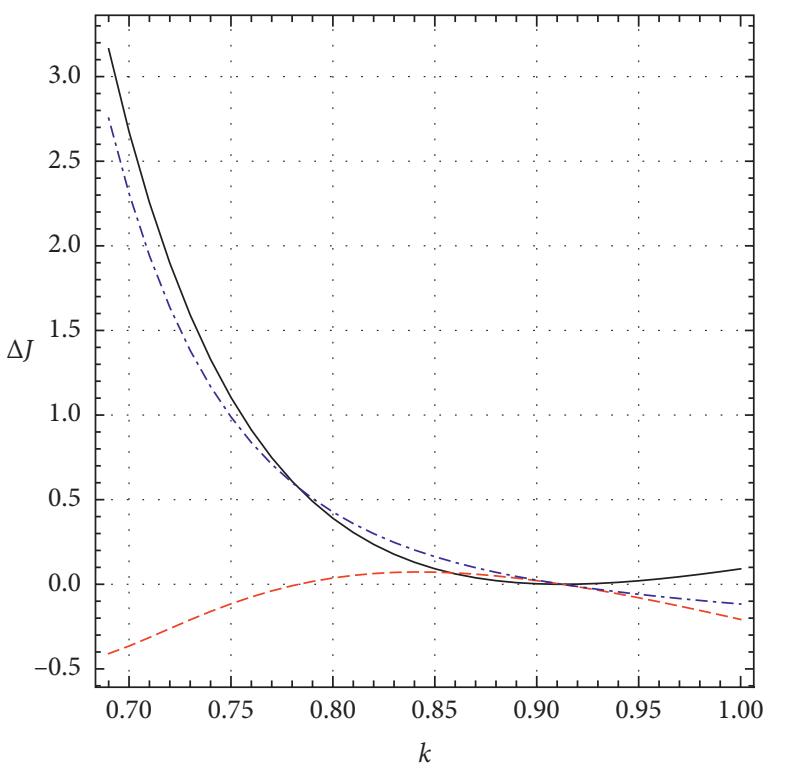

$$
\begin{aligned}
& -\Delta J_{\mathrm{m}} \\
& ---\Delta J_{\mathrm{r}} \\
& -\cdot-\Delta J
\end{aligned}
$$

FIGURE 6: Comparison of steady-state profits with $k$.

sales price competition intensity $b$ increasing. Specifically, when $b<0.08$, the wholesale price, sales prices, and green innovation level are higher under the dynamic pricing strategy as compared to the static one and vice versa. From Figure 4, we can observe that the manufacturer's profit with the dynamic pricing strategy is always higher than that with the static one. Interestingly, the retailer is better off adopting the dynamic pricing strategy when the degree of competition between the direct and retail channels is medium, and

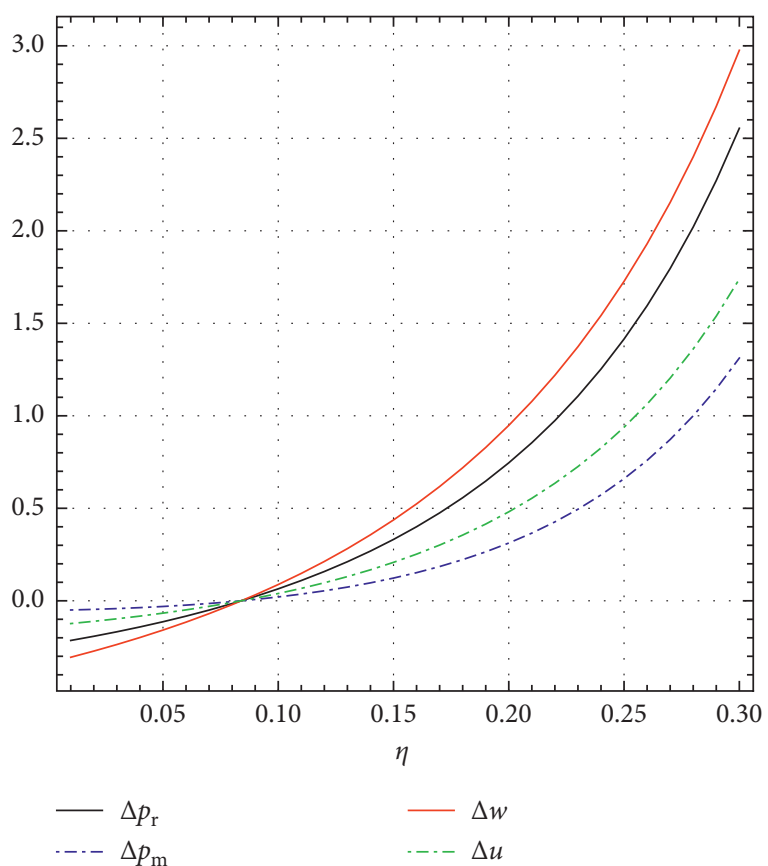

FiguRE 7: Comparison of steady-state decisions with $\eta$.

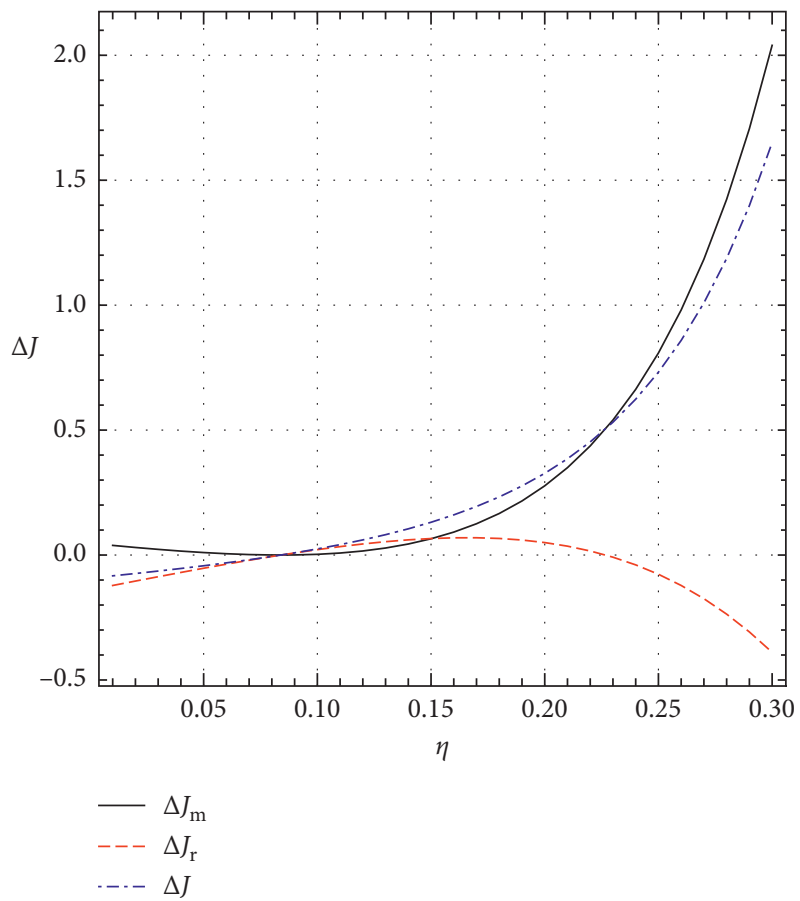

Figure 8: Comparison of steady-state profits with $\eta$.

otherwise worse off. For the whole supply chain, when $b>0.8$, the supply chain has a greater profitability with the dynamic wholesale pricing strategy, and otherwise the static wholesale pricing strategy combined with the transfer payment contract is the better choice.

Figures 5-8 show the differences of the steady-state decisions and profits of the supply chain between the two pricing strategies with the changes of the decay coefficient $k$ of energy efficiency level and the cost parameter $\eta$ of green 


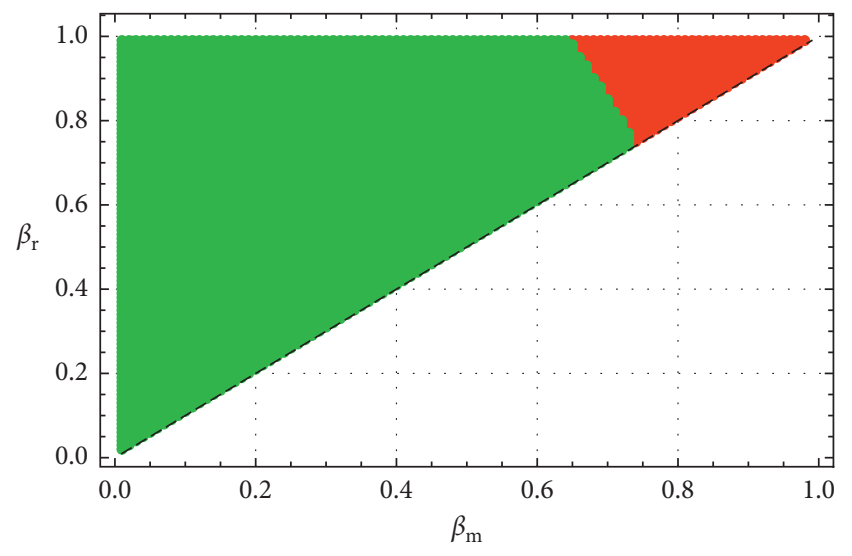

FIgURE 9: Comparison of steady-state profits with $\beta_{\mathrm{m}}$ and $\beta_{\mathrm{r}}$.

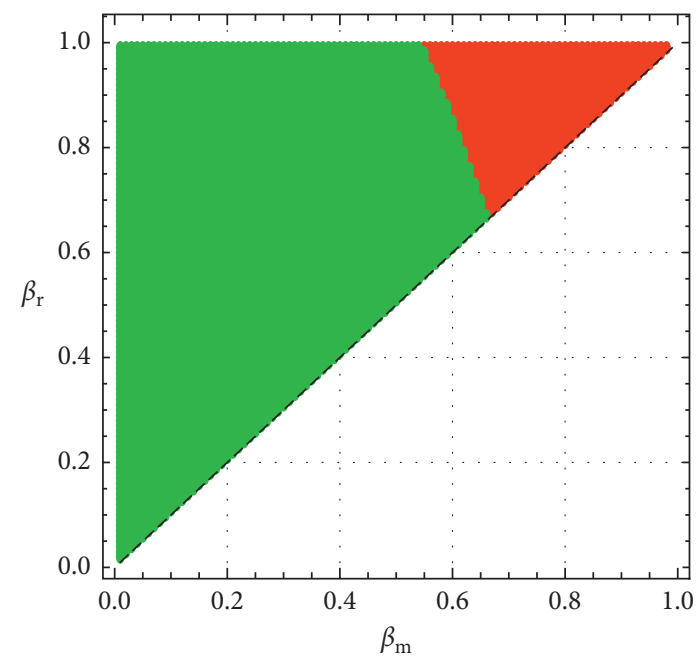

FIGURE 10: Comparison of steady-state profits with $\beta_{\mathrm{m}}$ and $\beta_{\mathrm{r}}$ when $\theta_{0}=8$.

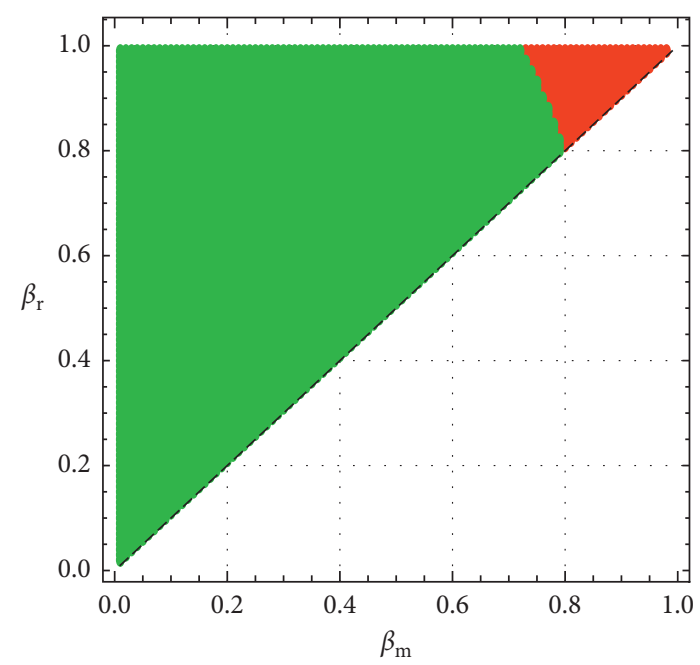

FIGURE 11: Comparison of steady-state profits with $\beta_{\mathrm{m}}$ and $\beta_{\mathrm{r}}$ when $\theta_{0}=12$. innovation. Similar to the above analysis, both the two parameter spaces are also divided into two parts using different pricing strategies. This provides some theoretical references for the supply chain members to choose the optimal strategy and further helps optimize the supply chain.

Due to the difference of consumption experience, consumers in the direct and retail channels have different energy efficiency perceptions. Figure 9 characterizes the effects of $\beta_{\mathrm{m}}$ and $\beta_{\mathrm{r}}$ on the profits of the supply chain members. Specifically, when the parameters $\beta_{\mathrm{m}}$ and $\beta_{\mathrm{r}}$ are in the red area, the members obtain more profits with the dynamic wholesale pricing strategy as compared to the static one; when $\beta_{\mathrm{m}}$ and $\beta_{\mathrm{r}}$ are in the green area, it is opposite for the members; the blank areas are meaningless due to the nonpositive equilibrium. It is intuitive to see that in Figure 9, the green area is larger than the red area, which means that the dynamic wholesale pricing strategy will be the better choice in most cases, and only when the effects of energy efficiency level on the demands in both channels are relatively large, the members prefer the static wholesale pricing strategy. By setting the value of the parameter $\theta_{0}$ from 8 to 12 , Figures 10 and 11 show that with a larger $\theta_{0}$, the division of strategic areas does not change much, but the green area becomes larger. This demonstrates that the higher the initial energy efficiency level of the product is, the more likely it is to adopt the dynamic wholesale pricing strategy.

\section{Conclusion}

With the enhancement of social environmental awareness, more and more people prefer to green products, and a growing number of manufacturers begin to produce green products. In this paper, we consider a dual-channel green supply chain, in which consumers of the direct and retail channels have different energy efficiency perceptions due to different purchasing experiences. The energy efficiency level of the product evolves over time and thus is characterized as a dynamic variable. The supply chain members need to make the wholesale price, sales prices, and green innovation decisions. We identify these decisions by developing and solving a Stackelberg differential game problem. By comparing the dynamic and static wholesale pricing strategies, we obtain some managerial insights. We further discuss the effects of some key system parameters on the supply chain, which also verifies the robustness of results in this paper.

Our main results show that the manufacturer has more incentives to invest in green innovation when more consumers buy the green product through the direct channel. With an increased energy efficiency level of the product, the manufacturer will charge a higher wholesale price and direct selling price, and the retailer will also set a higher retail price. By numerically comparing the profits of the supply chain members between the two wholesale pricing strategies, we find that the manufacturer prefers to adopt dynamic pricing in most cases and prefers static pricing only when the perceptions of the consumers of both channels are relatively high. However, there is an interesting finding that the static wholesale pricing strategy combined with the transfer payment contract is the better choice in some cases. In 
addition, our sensitivity analysis shows that the increases of discount rate $\rho$, decay coefficient $k$, and green innovation cost parameter $\eta$ will reduce the green innovation investment, wholesale price, sales prices, and the profits of each member and the whole supply chain; for the channel competition intensity $b$, it is the opposite for the supply chain; for a higher degree of consumer loyalty to the retail channel, the manufacturer will invest less in green innovation and charge a lower wholesale price but provide a higher direct selling price, and the retailer will set a lower retail price, which leads to a reduced profit of the manufacturer and increased profits of the retailer and the whole supply chain. The sensitivity analysis further verifies the robustness of the results of this paper.

Despite our research providing theoretical understandings and practical insights for the dual-channel green supply chain, there are some other factors to be taken into consideration. We can extend our study in the future by involving far-sight and short-sight behaviors of the supply chain members.

\section{Data Availability}

The data used to support the findings of this study are included within the article.

\section{Conflicts of Interest}

The authors declare that there are no conflicts of interest regarding the publication of this paper.

\section{Acknowledgments}

The authors are grateful to Professor Jianxiong Zhang for his efforts and valuable suggestions that improved this paper. This study was supported by the National Natural Science Foundation of China (grant no. 71971152), the Key Scientific Research Projects of Colleges and Universities of Henan Province (20B630002), and 2018 Research and Development Fund of Anyang Normal University (no. AYNUKP-2018-B25).

\section{References}

[1] M. Lieder and A. Rashid, "Towards circular economy implementation: a comprehensive review in context of manufacturing industry," Journal of Cleaner Production, vol. 115, pp. 36-51, 2016.

[2] H. Chen, E. C. Ayamba, A. O. Agyemang, S. O. Afriyie, and A. O. Anaba, "Economic development and environmental sustainability-the case of foreign direct investment effect on environmental pollution in China," Environmental Science and Pollution Research, vol. 26, no. 7, pp. 7228-7242, 2019.

[3] S. K. Srivastava, "Green supply-chain management: a state-ofthe-art literature review," International Journal of Management Reviews, vol. 9, no. 1, pp. 53-80, 2007.

[4] Q. Zhang, J. Zhang, and W. Tang, "Coordinating a supply chain with green innovation in a dynamic setting," $4 O R$, vol. 15, no. 2, pp. 133-162, 2017.

[5] M. Jain, A. B. Rao, and A. Patwardhan, "Consumer preference for labels in the purchase decisions of air conditioners in India," Energy for Sustainable Development, vol. 42, pp. 24-31, 2018.
[6] Y. Yu, X. Han, and G. Hu, "Optimal production for manufacturers considering consumer environmental awareness and green subsidies," International Journal of Production Economics, vol. 182, pp. 397-408, 2016.

[7] J. Hall, "Environmental supply chain dynamics," Journal of Cleaner Production, vol. 8, no. 6, pp. 455-471, 2000.

[8] D. Pujari, "Eco-innovation and new product development: understanding the influences on market performance," Technovation, vol. 26, no. 1, pp. 76-85, 2006.

[9] D. Yang and T. Xiao, "Pricing and green level decisions of a green supply chain with governmental interventions under fuzzy uncertainties," Journal of Cleaner Production, vol. 149, pp. 1174-1187, 2017.

[10] W.-Y. K. Chiang, D. Chhajed, and J. D. Hess, "Direct marketing, indirect profits: a strategic analysis of dual-channel supply-chain design," Management Science, vol. 49, no. 1, pp. 1-20, 2003.

[11] W.-Y. K. Chiang and G. E. Monahan, "Managing inventories in a two-echelon dual-channel supply chain," European Journal of Operational Research, vol. 162, no. 2, pp. 325-341, 2005.

[12] B. Li, M. Zhu, Y. Jiang, and Z. Li, "Pricing policies of a competitive dual-channel green supply chain," Journal of Cleaner Production, vol. 112, pp. 2029-2042, 2016.

[13] G. P. Cachon, "The allocation of inventory risk in a supply chain: push, pull, and advance-purchase discount contracts," Management Science, vol. 50, no. 2, pp. 222-238, 2004.

[14] L. Dong and K. Zhu, "Two-wholesale-price contracts: push, pull, and advance-purchase discount contracts," Manufacturing \& Service Operations Management, vol. 9, no. 3, pp. 291-311, 2007.

[15] K. Dey and S. Saha, "Influence of procurement decisions in two-period green supply chain," Journal of Cleaner Production, vol. 190, pp. 388-402, 2018.

[16] J. M. Cruz and T. Wakolbinger, "Multiperiod effects of corporate social responsibility on supply chain networks, transaction costs, emissions, and risk," International Journal of Production Economics, vol. 116, no. 1, pp. 61-74, 2008.

[17] G. Noci and R. Verganti, "Managing 'green' product innovation in small firms," R\&D Management, vol. 29, no. 1, pp. 3-15, 1999.

[18] N. J. Chang and C. M. Fong, "Green product quality, green corporate image, green customer satisfaction, and green customer loyalty," African Journal of Business Management, vol. 4, no. 13, pp. 2836-2844, 2010.

[19] T. Ramayah, J. W. C. Lee, and O. Mohamad, "Green product purchase intention: some insights from a developing country," Resources, Conservation and Recycling, vol. 54, no. 12, pp. 1419-1427, 2010.

[20] M.-B. Jamali and M. Rasti-Barzoki, "A game theoretic approach for green and non-green product pricing in chain-tochain competitive sustainable and regular dual-channel supply chains," Journal of Cleaner Production, vol. 170, pp. 1029-1043, 2018.

[21] Z. Hong and X. Guo, "Green product supply chain contracts considering environmental responsibilities," Omega, vol. 83, pp. 155-166, 2019.

[22] B. Liu, T. Li, and S.-B. Tsai, "Low carbon strategy analysis of competing supply chains with different power structures," Sustainability, vol. 9, no. 5, p. 835, 2017.

[23] R. He, Y. Xiong, and Z. Lin, "Carbon emissions in a dual channel closed loop supply chain: the impact of consumer free riding behavior," Journal of Cleaner Production, vol. 134, pp. 384-394, 2016. 
[24] Z. Basiri and J. Heydari, "A mathematical model for green supply chain coordination with substitutable products," Journal of Cleaner Production, vol. 145, pp. 232-249, 2017.

[25] S. Chen, X. Wang, Y. Wu, and F. Zhou, "Pricing policies of a dual-channel supply chain considering channel environmental sustainability," Sustainability, vol. 9, no. 3, p. 382, 2017.

[26] J. Zhou, Z. Zhang, and L. Yang, "Carbon emission reduction decisions in the retail-/dual-channel supply chain with consumers' preference," Journal of Cleaner Production, vol. 141, pp. 852-867, 2017.

[27] A. Dumrongsiri, M. Fan, A. Jain, and K. Moinzadeh, "A supply chain model with direct and retail channels," European Journal of Operational Research, vol. 187, no. 3, pp. 691-718, 2008.

[28] B. Dan, G. Xu, and C. Liu, "Pricing policies in a dual-channel supply chain with retail services," International Journal of Production Economics, vol. 139, no. 1, pp. 312-320, 2012.

[29] S. Althaher, P. Mancarella, and J. Mutale, "Automated demand response from home energy management system under dynamic pricing and power and comfort constraints," IEEE Transactions on Smart Grid, vol. 6, no. 4, pp. 1874-1883, 2015.

[30] C.-Y. Dye and C.-T. Yang, "Optimal dynamic pricing and preservation technology investment for deteriorating products with reference price effects," Omega, vol. 62, pp. 52-67, 2016.

[31] G. P. Cachon and P. Feldman: Dynamic Versus Static Pricing in the Presence of Strategic Consumers, Working Paper, 2010.

[32] J. Zhang, L. Lei, S. Zhang, and L. Song, "Dynamic vs. static pricing in a supply chain with advertising," Computers \& Industrial Engineering, vol. 109, pp. 266-279, 2017.

[33] S. Shaorui, V. Jayaraman, A. Paulraj, and K.-C. Shang, "Proactive environmental strategies and performance: role of green supply chain processes and green product design in the Chinese high-tech industry," International Journal of Production Research, vol. 54, no. 7, pp. 2136-2151, 2016.

[34] J. J. Cronin, J. S. Smith, M. R. Gleim, E. Ramirez, and J. D. Martinez, "Green marketing strategies: an examination of stakeholders and the opportunities they present," Journal of the Academy of Marketing Science, vol. 39, no. 1, pp. 158-174, 2011.

[35] J. Aguilera-Caracuel and N. Ortiz-de-Mandojana, "Green innovation and financial performance," Organization \& Environment, vol. 26, no. 4, pp. 365-385, 2013.

[36] N. Zhou, D. Fridley, M. McNeil et al., "Analysis of potential energy saving and $\mathrm{CO}_{2}$ emission reduction of home appliances and commercial equipments in China," Energy Policy, vol. 39, no. 8, pp. 4541-4550, 2011.

[37] W. Young, K. Hwang, S. McDonald, and C. J. Oates, "Sustainable consumption: green consumer behaviour when purchasing products," Sustainable Development, vol. 18, no. 1, pp. 20-31, 2010.

[38] A. A. Tsay and N. Agrawal, "Channel conflict and coordination in the e-commerce age," Production and Operations Management, vol. 13, no. 1, pp. 93-110, 2004.

[39] F. El Ouardighi, "Supply quality management with optimal wholesale price and revenue sharing contracts: a two-stage game approach," International Journal of Production Economics, vol. 156, pp. 260-268, 2014.

[40] D.-Q. Yao and J. J. Liu, "Competitive pricing of mixed retail and e-tail distribution channels," Omega, vol. 33, no. 3, pp. 235-247, 2005.
[41] D. Ghosh and J. Shah, "A comparative analysis of greening policies across supply chain structures," International Journal of Production Economics, vol. 135, no. 2, pp. 568-583, 2012.

[42] J. Song, F. Li, D. D. Wu, L. Liang, and A. Dolgui, "Supply chain coordination through integration of innovation effort and advertising support," Applied Mathematical Modelling, vol. 49, pp. 108-123, 2017.

[43] X. Li, B. Gu, and H. Liu, "Price dispersion and loss-leader pricing: evidence from the online book industry," Management Science, vol. 59, no. 6, pp. 1290-1308, 2013.

[44] M. T. Akçura, Z. D. Ozdemir, and M. S. Rahman, "Online intermediary as a channel for selling quality-differentiated services," Decision Sciences, vol. 46, no. 1, pp. 37-62, 2015.

[45] J. Chen, H. Zhang, and Y. Sun, "Implementing coordination contracts in a manufacturer Stackelberg dual-channel supply chain," Omega, vol. 40, no. 5, pp. 571-583, 2012.

[46] J. Lu, J. Zhang, and Q. Zhang, "Dynamic pricing for perishable items with costly price adjustments," Optimization Letters, vol. 12, no. 2, pp. 347-365, 2018. 


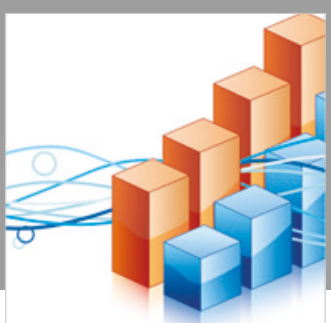

Advances in

Operations Research

\section{-n-m}
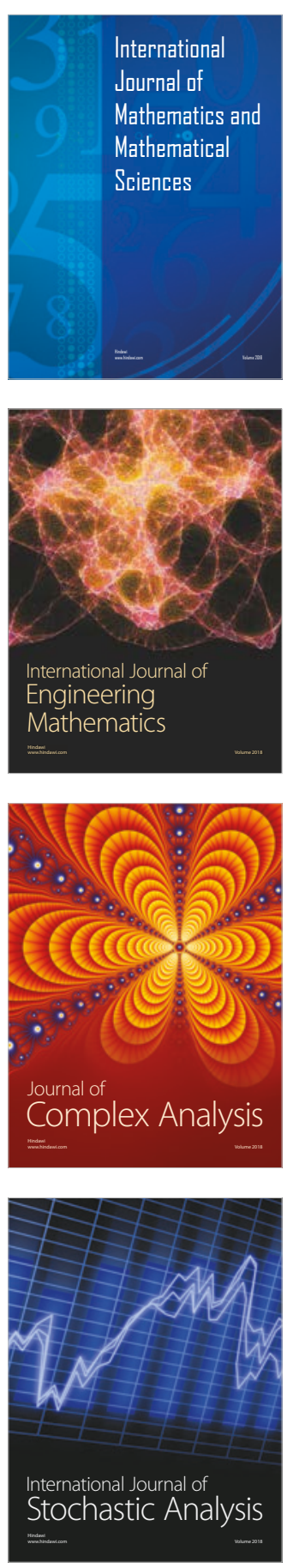
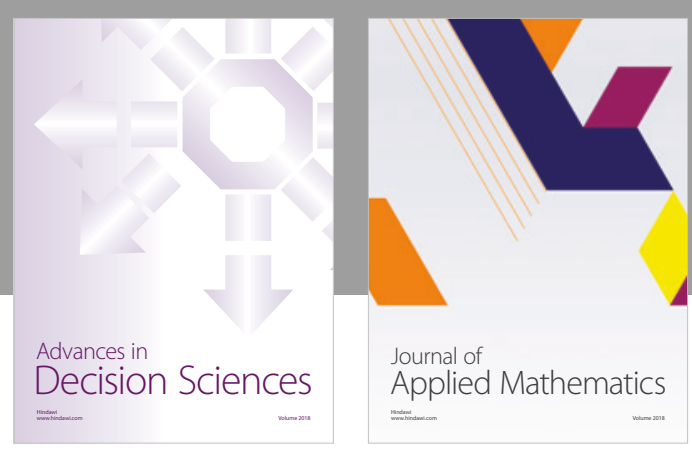

Journal of

Applied Mathematics
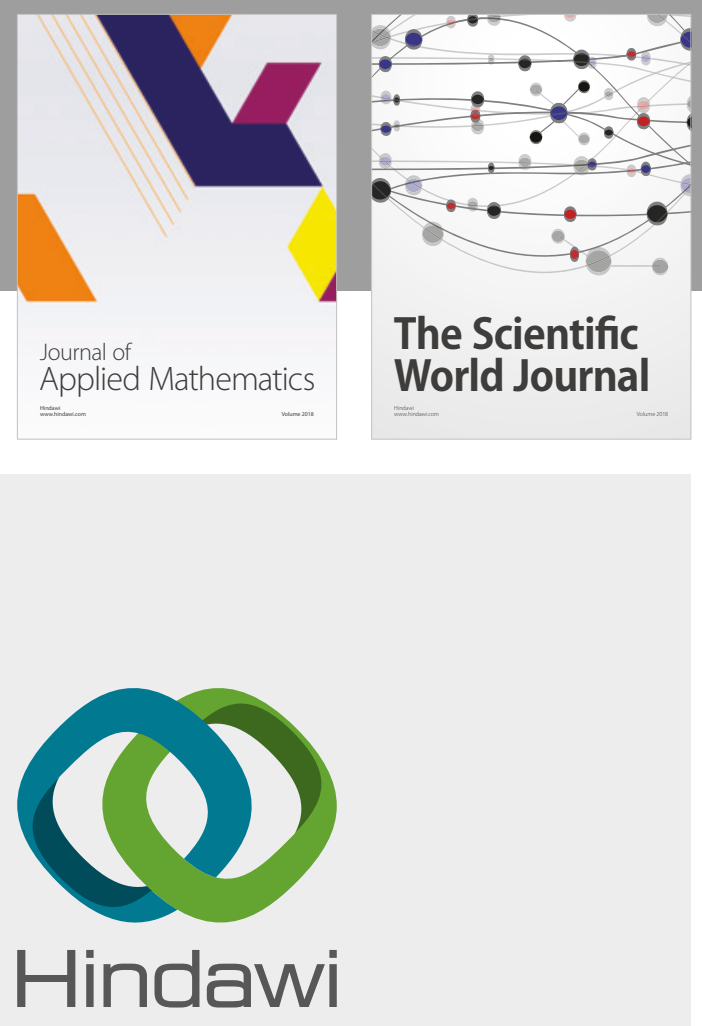

Submit your manuscripts at

www.hindawi.com

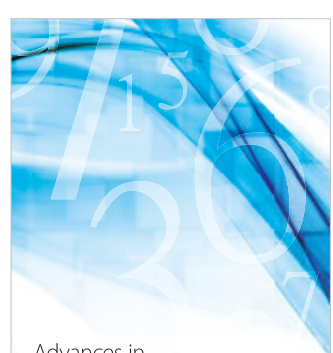

Advances in
Numerical Analysis
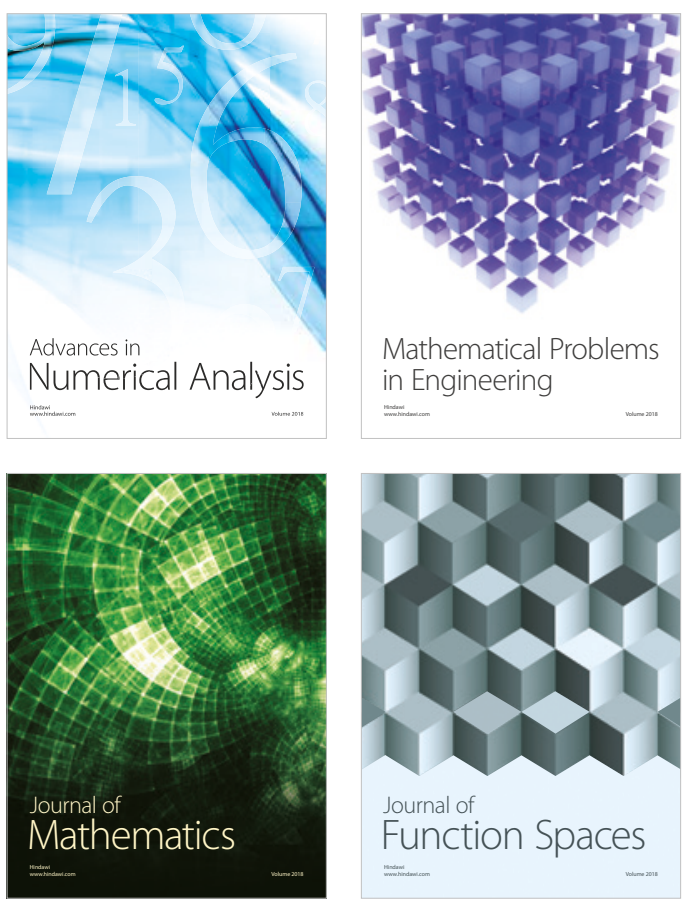

Mathematical Problems in Engineering

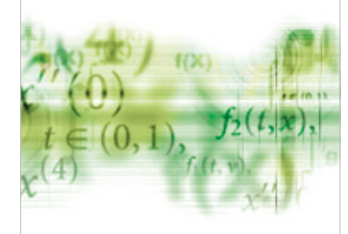

International Journal of

Differential Equations

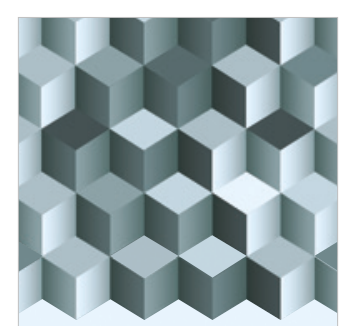

Journal of

Function Spaces
The Scientific

World Journal

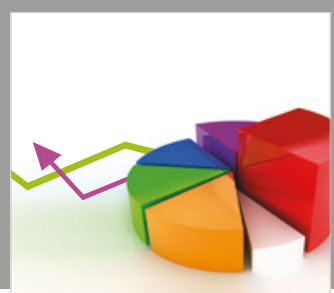

Journal of

Probability and Statistics
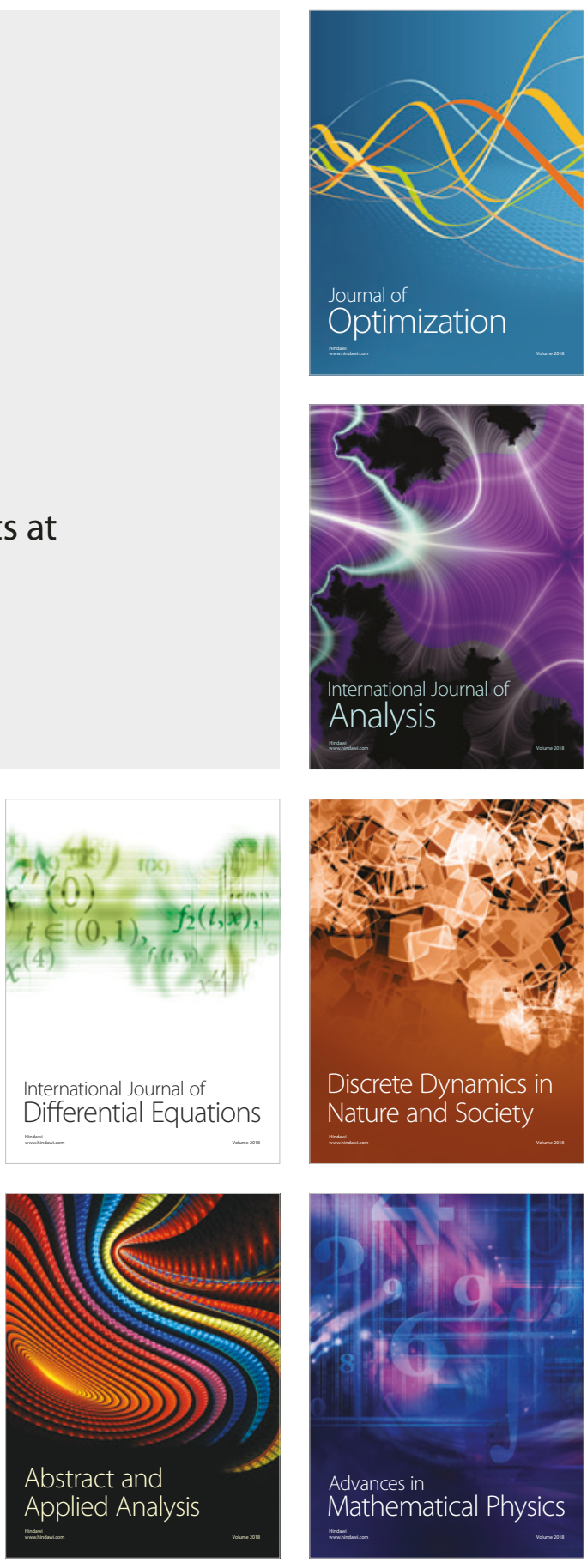